\title{
Fostering parents-professional collaboration for facilitating the school inclusion of students with ASD: design of the "ToGather" web-based prototype
}

\author{
Cécile Mazon ${ }^{1,2}$ (D) Kattalin Etchegoyhen ${ }^{3} \cdot$ Isabeau Saint-Supery ${ }^{1,2}$. \\ Anouck Amestoy $^{3} \cdot$ Manuel Bouvard $^{3}$. Charles Consel ${ }^{4} \cdot$ Hélène Sauzéon $^{1,2}$
}

Accepted: 21 November 2021 / Published online: 2 December 2021

(c) Association for Educational Communications and Technology 2021

\begin{abstract}
In recent years, many psycho-educational technologies were studied to address the schoolrelated difficulties encountered by students with autism spectrum disorder (ASD). However, most of them remain individual-centered and do not consider the social environment. To fill this gap, this study reports on the user-centered design of a web-based support tool, which aims to support communication and coordination between parents, school staff and health professionals of middle and high school students with ASD, in the context of elaborating, implementing, and following an Individualized Education Plan. The study followed a two-step design process: (1) a need analysis for identifying information domains deemed important by the stakeholders; (2) through a participative iterative design process, a panel of professionals and parents provided ideas and feedbacks on the design, which was integrated in subsequent prototype versions of the "ToGather" app.
\end{abstract}

Keywords Parent-professional relationships · User-centered design · School inclusion · Autism spectrum disorder $\cdot$ Ecosystemic approach

Cécile Mazon

cecile.mazon@u-bordeaux.fr

$\triangle$ Hélène Sauzéon

helene.sauzeon@u-bordeaux.fr

1 Équipe Handicap, Activité, Cognition, Santé (HACS), Université de Bordeaux, Inserm, BPH, U1219. Site Carreire, zone Nord, bat. 1B. 146 rue Léo Saignat, 33076 Bordeaux, Gironde, Nouvelle-Aquitaine, France

2 Équipe-Projet Flowers, Inria Bordeaux Sud-Ouest, 200 Avenue de la Vieille Tour, 33405 Talence Cedex, Gironde, Nouvelle-Aquitaine, France

3 Centre Ressources Autisme Aquitaine, Centre hospitalier Charles Perrens, 121 rue de la Béchade, CS81285, 33076 Bordeaux Cedex, Gironde, Nouvelle-Aquitaine, France

4 Bordeaux INP/Enseirb-Matmeca, Avenue des Facultés, 33405 Talence Cedex, Gironde, Nouvelle-Aquitaine, France 


\section{Background}

Since the late 1970s, psycho-educational technologies for children and adolescents with autism spectrum disorder (ASD) and cognitive disabilities elicited a growing interest. A large number of studies was conducted to assess a variety of applications on several digital media, such as computers, tablets, smartphones, smartwatches, robots (for review, Mazon et al., 2019). Systematic reviews dedicated to these technologies have proliferated as well, with a growing number of systematic reviews and meta-analyses, assessing their efficacy (e.g., Grynszpan et al., 2014; Lee et al., 2018; Mazon et al., 2019; Odom et al., 2015). Whatever their purpose (i.e., rehabilitation or assistance), psycho-educational technologies are mostly focused on the difficulties and limitations of individuals with ASD. They remain therefore in a dynamic of unilateral compensation of the disability: it is up to the individuals to rehabilitate themselves through training and/or assistance to adapt to their environment. This approach does not fit with current conceptual frameworks related to disability, such as the ICF (International Classification of Functioning, disability, and health, WHO, 2001) and the ICF-CY (International Classification of Functioning, disability, and healthChildren and Youth version, WHO, 2007), which consider the disability as the result of the interaction between the individuals and their physical and social environment. Without minimizing the need for "individual-centered" interventions, the field of psycho-educational technologies for individuals with ASD could be enriched with new solutions that consider the socio-environmental barriers related to their participation restrictions. This might stem from the fact that socio-environmental dimensions related to disability are difficult to operationalize, as they are numerous, multi-scaled (e.g., political, social, community, family, individual), and may form complex interactive loops (Bronfenbrenner, 1977, 2005).

This work aimed to open new perspectives into the field of psycho-educational technologies for individuals in ASD, by proposing the design of a digital tool for inclusive education that addresses the needs of stakeholders surrounding the child. In the following sections, we reported on the preliminary steps of a user-centered process to design a web-based application prototype for supporting communication and coordination between parents, school staff, and health professionals in the elaboration and the follow-up of the Individualized Education Plan (IEP) of children with ASD.

\section{School inclusion of children and adolescents with ASD}

ASD is an early-onset neurodevelopmental disorder, characterized by difficulties in the communication and social interaction domain, as well as a pattern of restrictive, repetitive, and stereotyped behaviors, activities, and interests (APA, 2013). The atypical cognitive profile and adaptive functioning of children with ASD often result in a limited adaptation to the normative school system. School inclusion in mainstream settings is increasingly recommended to foster social participation and to improve the socio-professional future of children and youth with ASD (e.g., Chamak \& Bonniau, 2016; Hunt \& McDonnell, 2007; Reed \& Osborne, 2014). The enrollment in inclusive settings may indeed promote the development of academic, social, adaptive, emotional as well as relational abilities in children with ASD, and improve the prognosis in terms of independence and autonomy in adulthood (e.g., Chamak \& Bonniau, 2016; Howlin \& Magiati, 2017; McCurdy \& Cole, 2013). Even if policy efforts are made towards more inclusive education, their particular 
Table 1 Environmental systems from the ecosystemic model

1. Ontosystem the individual and their characteristics

2. Microsystem immediate settings containing the individual (e.g., family, school, community)

3. Mesosystem interrelations among the major settings containing the individual (e.g., family-school relationships)

4. Exosystem extension of the mesosystem to settings that do not contain the individual. This refer to both formal and informal social structures which impinge upon or encompass individual's immediate settings (e.g., society institutions, world of work, media, government agencies)

5. Macrosystem cultural and ideological context of the society

6. Chronosystem temporal dimension of the model, which consider individual development and associated changes over time

profile may compromise their enrollment in mainstream schools (e.g., Harrower \& Dunlap, 2001; McCurdy \& Cole, 2013). For instance, students with ASD often struggle to carry out school activities autonomously. This is compounded with difficulties in engaging in school activities, as well as in establishing relationships with their peers and interacting with the school staff (e.g., Jahromi et al., 2013; Van Hees, et al., 2015).

The ICF-CY conceptual framework (WHO, 2007) allows identifying ASD-related social and adaptive limitations as a primary barrier to their school inclusion in mainstream settings, which are even more exacerbated as the symptom severity increases (e.g., Kurth et al., 2019). Concurrently, the issue related to the school inclusion of students with ASD is also related to both latent and manifest socio-environmental factors. For instance, there is a lack of material and human resources for students' support, a lack of training of school staff, difficulties in inter-professional and family-professional coordination, or even, in a latent way, misbeliefs, stereotypes, and prejudices from adults and peers regarding disability and autism (Roberts \& Simpson, 2016). These accumulating environmental obstacles lead to difficulties in the daily lives of included students with ASD and may compromise the quality and the continuity of their schooling.

\section{Ecosystemic approach for understanding environmental factors}

Although ICF-CY points out socio-environmental factors as barriers to children's participation, this framework does not provide in-depth methods for accurate identification of environmental determinants and their possible relationships as barriers or facilitators to inclusive education. The ICF-CY category of "environmental factors" has been criticized for its lack of granularity and operationalization (Magasi et al., 2015; Whiteneck \& Dijkers, 2009). The ecosystemic approach can provide an alternative way to address the ICFCY limitations related to socio-environmental influences. This approach, based on Bronfenbrenner's model $(1977,1979,2005)$, proposes to study individual development through a systemic and ecologic perspective. In this framework, Bronfenbrenner (1977, 1979, 2005) defines the bioecological model as a framework for studying the course of human development over time and in close relation to the individuals' living environment. Human development is seen as the "phenomenon of continuity and change in the biopsychosocial characteristics of human beings, both as individuals and as groups." (Bronfenbrenner, 2005, p. 3). In this framework, the individuals and their development are seen through a complex system, which is decomposed into several nested and interconnected subsystems (Table 1). Ecosystemic approaches have been successfully adapted to the particular 
situation of students with ASD to identify facilitators and obstacles to their school inclusion in mainstream settings (for a review, see Cappé \& Boujut, 2016). This approach also allows to hierarchize the multiple socio-environmental influences that are likely to affect the participation of students with ASD, but also to holistically consider socio-environmental barriers to school inclusion. Then, we could identify direct and indirect factors, and suggest potentially relevant targets for intervention or support.

The first system, the ontosystem, consists of the individual himself. We already emphasized the wealth of psycho-educational technologies, which address individual difficulties of students across various domains. Although the global model considers the interactions between the individual and other nested subsystems, the ontosystem includes only the individual and his development.

The second system, the microsystem, considers the individual's immediate and proximal settings and the relationships both between the individual and these settings and between all people embedded in every single setting. For a student with ASD included in mainstream settings, the main microsystems are home, school, and medico-social settings (e.g., specialized educators, rehabilitative professionals, health centers). Digital tools have been designed in past studies for addressing the needs of each setting, with (1) for the parents, teleassistance and online training related to the daily support of a child with ASD and the implementation of home-based interventions (Bearss, et al., 2015; Corralejo \& Rodriguez, 2018; Patterson et al., 2012); (2) for the school setting, digital systems designed to host and manage a student with ASD in class (Hirano, et al., 2010); and (3) in medico-social setting, monitoring and follow-up systems for improving the diagnosis and the functional assessment (e.g., Serna et al., 2015).

The third system, the mesosystem, considers the relationships between the individual's major immediate settings. The mesosystem mainly concerns the relationships between the family and the school, between the family and the medico-social practitioners, as well as relationships between the school and the medico-social settings. These stakeholders are implied in the follow-up and the support of the students with ASD following their individualized education plan (IEP) and their expertise. Interprofessional and family-professional partnerships are essential for supporting individuals with ASD (Gomes \& McVilly, 2019; May, et al., 2019).

The care and the support of children with ASD imply a multidisciplinary approach to diagnose disorders and assessing their capacities, to design clinical and educational interventions, as well as to continuously support the needs of the children (e.g., Bernie et al., 2019). However, families and professionals often report difficulties in developing and implementing an IEP for students with ASD. These difficulties are frequently related to opinion divergences and communication barriers between the different stakeholders. As a result, the support teams struggle to coordinate individual efforts to best support children with ASD (Azad \& Mandell, 2016; Bernie, et al., 2019; Long, et al., 2017; Prado, 2013). Using a Delphi survey technique, Gomes and McVilly (2019) highlighted several characteristics that may foster effective team practices in disability support teams: (1) a shared focus on patient outcomes, (2) good communication among the team, and (3) effective leadership. Other factors have been identified in this study, such as the commitment to support, concerns for the well-being of the care recipient and professional stakeholders, as well as the willingness to engage in collaborative activities (Gomes \& McVilly, 2019).

The mesosystem is nested in two other systems, that is, the exosystem and the macrosystem. As the ecosystemic model implies interconnected systems, both systems may impact dynamics in the mesosystem. The exosystem refers to both formal and informal social rules and dynamics which shape the local functioning of immediate settings of the developing 
individual. In other words, the exosystem refers to formal laws and legislations and to informal social rules which determine how local settings are functioning (e.g., work world, communities). The principles of inclusive education, which are promoted by laws and legislation, promote the full adaptation of instructional strategies to the diversity of special needs, as well as the collaboration between professionals and families for supporting the schooling of children with disabilities. However, these principles are not easily translated into practices, and few tools and strategies are provided to the field workers and families (Allenbach et al., 2016; Prado, 2013). Finally, the macrosystem refers to the political and moral values and the social representations driven by the culture and the society. This system influences all other systems: social representations of ASD and disability are often negative, and affect individual behavior (e.g., Park \& Chitiyo, 2011). Several studies have already emphasized the role of prejudices, stereotypes, and attitudes to disability on the quality and the success of schooling of children with disabilities (Freitag \& Dunsmuir, 2015; Jury et al., 2021). However, this system is also the most difficult to change, as social representations and individual attitudes are robust and slowly evolve.

As the exosystem and the macrosystem are not "tangible" systems, it is quite difficult to directly address them with interventions. The dynamics between environmental systems can be either a virtuous or a vicious circle, and a change in one system can impact both upper and lower systems. Then, supporting the collaboration between stakeholders (mesosystem) in the elaboration and the follow-up of the IEP may then induce positive changes on all other systems.

\section{Home-school partnerships and digital practices}

To date, few studies have addressed mechanisms and factors that foster effective disability support teams (May et al., 2019). Home-school partnerships, and in particular parentteacher relationships, have been explored in the context of school inclusion of students with ASD. Several studies showed that parent-teacher relationships influence students' academic success (e.g., Azad et al., 2016; Minke et al., 2014). Having good parent-teacher relationships offer continuity between the student's living environments, which is beneficial to their development at several levels (e.g., academic, social, emotional, behavioral). However, several studies showed that parents of children with ASD as well as teachers are quite dissatisfied with their relationship and communication, and even more as the child grows older (e.g., Azad \& Mandell, 2016; Azad et al., 2018; Kurth et al., 2019; Schultz et al., 2016; Tucker \& Schwartz, 2013; for review, see Roberts \& Simpson, 2016).

Although they are volunteers to participate, parents of children with ASD often report conflicts with the school staff and disagreements on the IEP implementation within the school (Tucker \& Schwartz, 2013). Parents also report a lack of consideration regarding their opinion and a feeling that they cannot fully participate in the decisions that affect their child (Kurth et al., 2019). In turn, these difficulties negatively affect home-school relationships as well as parents' satisfaction regarding their child's schooling (Kurth et al., 2019). For their part, teachers frequently report a lack of time and training to effectively communicate with parents (Azad, et al., 2018). They often perceive parents as being over- or under-implicated in their child's schooling (e.g., Bezdek et al., 2010; Schultz, et al., 2016). Parents and teachers agree, though, on the importance of collaboration and communication in fostering effective inclusive education for students with ASD (Roberts \& Simpson, 2016). Despite the reported difficulties in home-school partnerships, a few support 
tools have been designed to improve communication and relationships between parents and teachers toward developing, implementing, and monitoring an IEP (Azad et al., 2018).

Digital technologies represent an appealing vehicle of interventions for promoting interactions between families and professionals. The Covid-19 crisis has accentuated this need for technology tools, as the support needs of children with ASD required more efforts from families, teachers, and health practitioners to ensure the continuity of education and care (Hill et al., 2021; Parmigiami et al., 2020; Petretto et al., 2020). Parents and professionals both expressed that the loss of contact with each other impeded their ability to provide adequate support to the children (Hill et al., 2021; Parmigiami et al., 2020). Olmstead (2013) observed that parents and teachers consider technologies as an effective way to foster communication and parental involvement. This study also showed that they mainly use mainstream technologies, such as e-mails, social networks, and blogs, to communicate and coordinate with each other (Olmstead, 2013). However, these tools have not been designed to provide a longitudinal follow-up of a student with a disability included in mainstream settings. They cannot effectively support the gathering of and access to student information produced and shared by stakeholders, across school years and educational stages. Blogs and social networks are used by teachers for providing parents with information about the range of activities carried out in the class. However, these mediums are not recommended when exchanging more sensitive information about a particular student, if the information is shared by all parents. Messaging systems, such as e-mails or instant messaging, allow more private conversing and defining specific recipients of the information. However, despite the possibility to keep and sort messages, these systems lose their utility when used over an extended time. Information is not organized according to semantic criteria but chronologically so that one should sometimes go back through long threads of conversation to find old information. Another drawback of messaging systems is that they make explicit usage of recipient names; any change in the team composition can create technical challenges to recover and continue specific conversations. Moreover, information is not only transmitted through the messaging channel but also orally during an interview or a meeting, for example. This situation may create gaps in the information accessible to the stakeholders of students' support teams. Existing tools in school settings (e.g., Pronote, École Directe, Sacoche ${ }^{1}$ ) are rather oriented towards managing the academic aspects of a student (e.g., tracking grades and skills, course schedules and absences, textbooks, homework, and even course content), and not towards the follow-up and the multidisciplinary support needed for the IEP of a student with a disability.

According to our reviewing of studied existing products, we found that CryptoHeaven, a provider of secured e-mail and file-sharing services, has been used in a study evaluating the added value of e-collaboration in an IEP organization (Catagnus \& Hantula, 2011). Encouraging results are reported, such as an increase of discussion and saved time in building a behavior intervention plan. However, this study involves only professionals (i.e., teachers, speech and language therapists, and occupational therapists) and not the parents in the IEP process. Also, as CryptoHeaven is primarily a provider of messaging services, it may be subject to the drawbacks of mainstream messaging systems that we previously mentioned.

\footnotetext{
1 Pronote, École Directe and Sacoche are French software designed for managing students' academic progress for teachers and parents according to a predefined competences program for all students. A growing number of French schools are equipped with this kind of software.
} 
Therefore, to the best of our knowledge, there is no digital tool or intervention designed to promote collaboration, communication, and interaction between the school, the family, and the medico-social settings toward improving support for students with ASD in inclusive education. The objective of this work is therefore to design a collaborative information-sharing, digital tool dedicated to facilitating the development, implementation, and monitoring of an IEP of students with ASD.

\section{Design methodology}

This paper describes design-based research aiming at developing an innovative environment to support the school inclusion of children with ASD by acting on the mesosystem of the child. Design-based research is defined as a paradigm to study learning in context and instructional strategies and tools, through the design and the exploration of innovative tools and strategies (Design-based research Collective, 2003; Sandoval \& Bell, 2004). This kind of research attempts to link the theoretical background to experience through the design and implementation of actions in the learning environment, by leveraging both empirical research methods and design frameworks. Design thinking and participative design methods are now widely used in the field of technological design for special education and people with special needs (Bjögvinsson et al., 2012; Edelson, 2002; Wróbel \& Romanowski, 2015). These methods allow for creative problem-solving and are effective in resolving difficult and open problems (Wróbel \& Romanowski, 2015). Design thinking and user-centered design methods share many aspects in their process and implied similar methods for understanding the needs of users and designing solutions with users in an iterative manner. We adopted user-centered methods involving survey techniques and iterative participatory design cycles to design a tool that addresses the needs of both familial and professional caregivers of a student with ASD. Participatory design is a method, which consists of involving future users at all the design steps of a product or service (Bjögvinsson et al., 2012; Rahimi \& Ibarra, 2014; Spinuzzi, 2005). Involving end-users at the earliest stages makes it easier to come up with a product that will be tailored to their needs and expectations, and in the long run, facilitate product adoption. The process of participatory design is structured through four main stages (Spinuzzi, 2005): (1) needs analysis; (2) idea generation; (3) modeling and prototyping; (4) evaluation. These stages form an iterative design loop until obtaining a product fully adapted to the users' needs, expectations, and preferences.

Following user-centered design techniques, this work began with a needs analysis of inclusive education stakeholders involved in the follow-up of a student with ASD, including parents, teachers, and school aides, as well as relevant health practitioners. We developed a questionnaire to collect their needs in terms of information required to support a child with ASD at school. From these results, we extracted the first version of design principles and sketched an initial prototype of the tool (idea generation). Several iterations with end-users were conducted to collect their opinions and ideas to improve the design and produce a prototype (modeling and prototyping). Figure 1 summarizes the full process of this participatory design-based research. 


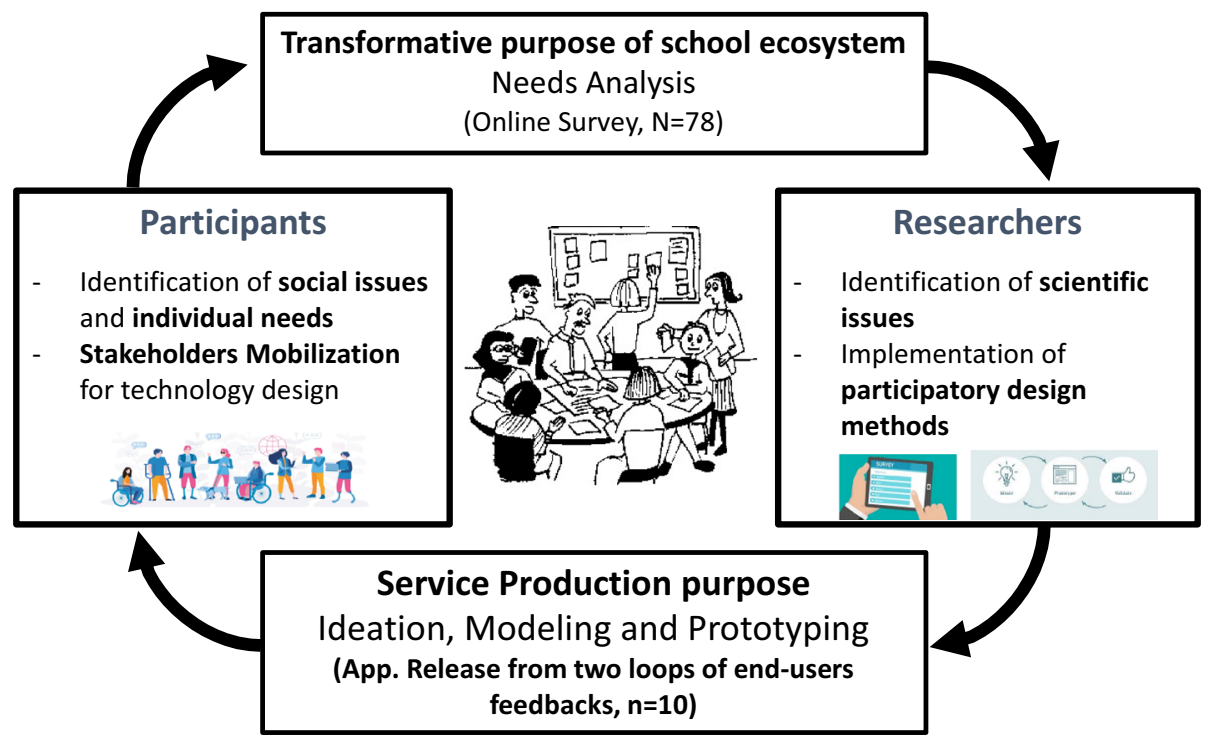

Fig. 1 Participatory design-based research process of "ToGather" app

\section{Needs analysis}

In this first design step, we collected inclusive education stakeholders' needs in terms of information needed to follow and support a student with ASD included in mainstream school. To this end, we questioned familial and professional caregivers (i.e., parents, school, and health professionals) about their difficulties and the information they would like to have to best support students with ASD in their schooling. The purpose of this first stage was twofold:

(1) Highlight information needs of familial and professional caregivers to support a student with ASD enrolled in middle or high school in mainstream settings.

(2) Determine whether the expressed needs are shared by all caregivers across the different settings (i.e., family, school, medico-social).

\section{Method}

\section{Participants}

We solicited 124 individuals who were likely to be implicated in the care and/or the followup of a child with ASD, enrolled in middle or high school: parents, special education teachers, mainstream teachers, school assistants, referent teachers, ${ }^{2}$ and health practitioners. The

\footnotetext{
${ }^{2}$ In France, referent teachers are teachers whose mission is to follow students with disabilities schooled in their geographic area and to ensure the conformity in the implementation and the monitoring of their IEP. They no longer teach and work full time on this mission.
} 
recruitment of those individuals was done via an email campaign. The link to the questionnaire was accompanied by an explanatory text of the procedure and the agreement of the head of special education for Bordeaux. The study protocol was approved by the ethical committee of Inria Center (French research Institute in mathematical and computer science).

The recruitment of teachers and school assistants was made in the public-school system of Bordeaux and approved by the head of special education for this sector. Special education teachers have been contacted based on a list of special education classrooms in the southwest French regions. These specialized classrooms are embedded in a mainstream school and enroll students with various disabilities. Students with ASD are frequently included in these settings to benefit from a special education setting while attending mainstream classes.

Parents and other professionals were recruited via the Autism resources center of Nouvelle-Aquitaine, affiliated with the public health system. The school assistants were recruited through the training sessions provided by the Autism resources center. The participating families were those of adolescents with ASD followed in this structure. Finally, the health practitioners recruited are part of the network of professionals of the Autism resources center.

\section{Development of the questionnaire}

The questionnaire was developed by our team to probe the information needs of individuals involved in the support of a student with ASD enrolled in middle or high school (see Online Appendix 1). The first part of the questionnaire collected general information about the respondent: (1) occupation, (2) experience in supporting youth with ASD, and (3) ASD-specific training received.

The second part of the questionnaire focused on the difficulties encountered and the information deemed useful when supporting a student with ASD in middle or high school. Firstly, two open-ended questions were proposed to the respondents, concerning: (1) the difficulties they encountered and (2) the information they deem useful when supporting a student with ASD. Secondly, thirteen closed questions assessed the usefulness of information across 13 themes related to the support of students with ASD: general information on $A S D$, level of autonomy, non-verbal communication, school level and experience, external interveners, health, language abilities, everyday functioning, cognitive abilities, aids and adjustments, verbal language level, social abilities, daily events. Those close-ended questions were completed with an open-ended question that allows to detail which information is deemed useful about the topic of the question.

\section{Answers' treatment and data analysis}

The answers to the open-ended questions were treated through a qualitative content analysis of the participants' responses, by extracting the main themes related to the difficulties encountered and the information needs expressed by the respondents. After an initial reading of all answers, we defined a set of recurring themes across participants' answers. Then, we coded each answer based on the identified theme(s) that were contained in its content. The themes extracted from open-ended questions have also been related to the 13 themes proposed in the close-ended questions. One researcher coded the entire set of answers, 
and the coding was reviewed by two other researchers. Conflicts about the coding were resolved through discussion between the coder and the reviewers.

We compared the answers according to the respondents' settings (i.e., family, school, health professionals), by using $\chi^{2}$ independence tests and Fischer's exact tests depending on the number of answers. The objective of these analyses was to determine whether the respondents from each setting expressed or not the same information needs. When discrepancies were highlighted, we computed the relative risk (RR) associated with the difference.

\section{Results}

The response rate to the questionnaire was approximately 63\%, with 78 participants answering all the questions. Figure 2 shows the distribution of respondents according to their occupation. The various professionals from the school setting represent about $51 \%$ of the respondents, the parents about $32 \%$, and health practitioners about $17 \%$.

The professional respondents have on average about 3,7 years of experience with students with ASD (ranging from a few months to several years). Around $44 \%$ of the respondents have received ASD-specific training. All the health practitioners surveyed and about $44 \%$ of the parents have received this kind of training. Among school professionals, about $35 \%$ of the respondents have received ASD-specific training.

\section{Open-ended questions}

The first open-ended question was submitted to parents and school staff, about the difficulties encountered when supporting a child with ASD in inclusive education. The qualitative content analysis allowed us to extract 7 recurring themes among respondents from family and school settings (Fig. 3). Once answers were coded according to identified themes, the most frequent difficulties encountered were: (1) communication abilities (62\%), (2) autonomy to work (52\%), (3) relational abilities (43\%), and (4) behavioral problems $(35 \%)$. Some disparities were highlighted between parents and school professionals: parent-reported significantly more often the relational difficulties encountered by their child $\left(\chi^{2}=8.70 ; p<.01, \varphi=0.398 ; \mathrm{RR}=2.47\right)$, whereas school professionals mentioned more often difficulties related to behavioral problems (Fischer's test, $p<.05, \varphi=0.298$; $\mathrm{RR}=2.81$ ).
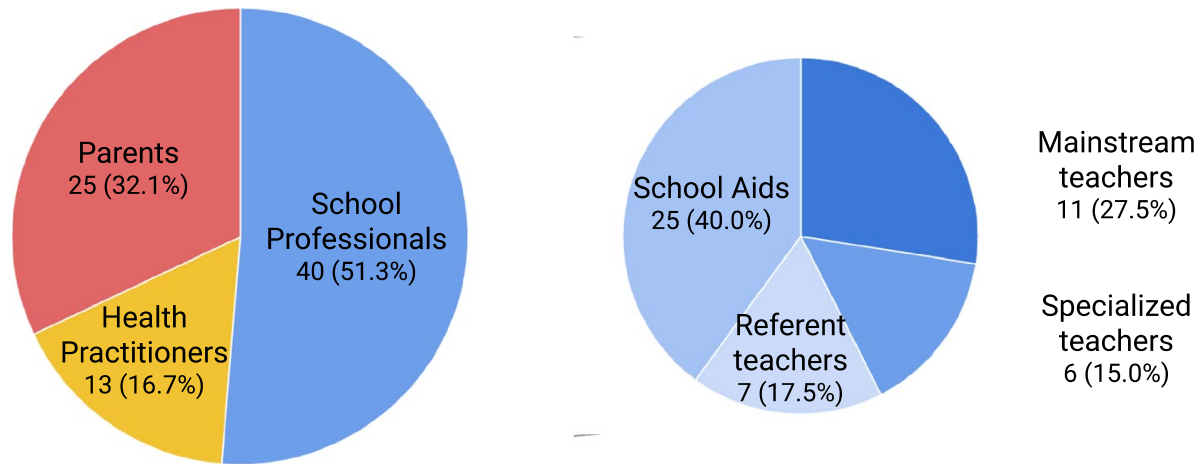

Fig. 2 Distribution of the respondents by setting and occupation: family setting (parents), medico-social setting (health practitioners), and school setting (teachers, school aides) 


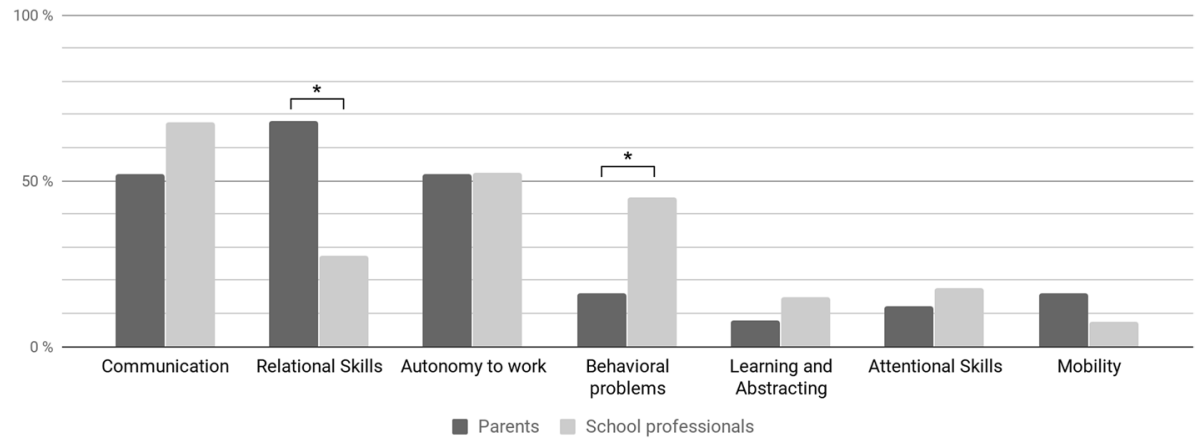

Fig. 3 Recurring themes reported in the open-ended question about the difficulties encountered by the respondents, with the distribution between parents and school professionals

The second open-ended question was submitted to all respondents (i.e., parents, school staff, and health practitioners), about information needs when supporting a child with ASD in inclusive education. The qualitative content analysis allowed us to extract 11 recurring themes mentioned by the respondents (Fig. 4). Once answers were coded according to identified themes, the most cited information domains were: (1) aids and adjustments (50\%), (2) the skill profile (46\%), (3) general information about ASD (35\%), and (4) the school level and experience $(26 \%)$.

Again, we highlighted disparities between the categories of respondents. Parents and health professionals both mentioned significantly more often a need for information about ASD in comparison with school professionals $\left(\chi^{2}=7.88, p<.05, \mathrm{~V}=0.318\right.$; $\mathrm{RR}=2.60$ [parents vs. school pro.]; 2.31 [health pro. vs. school pro.]). All professional stakeholders reported significantly more often information needs about the school level and experiences in comparison with parents (Fischer's exact test; $p<.05, \mathrm{~V}=0.301 ; \mathrm{RR}=4.69$ [school pro. vs. parents]; 2.88 [health pro. vs. parents]). Finally, parents were the most supportive of the need for information about how their child expresses emotions, and notably fatigue and stress (Fischer's exact test; $p<.05, \mathrm{~V}=0.358, \mathrm{RR}=5.60$ [parents vs. school pro.]; 8.08 [parents vs. health pro.]).

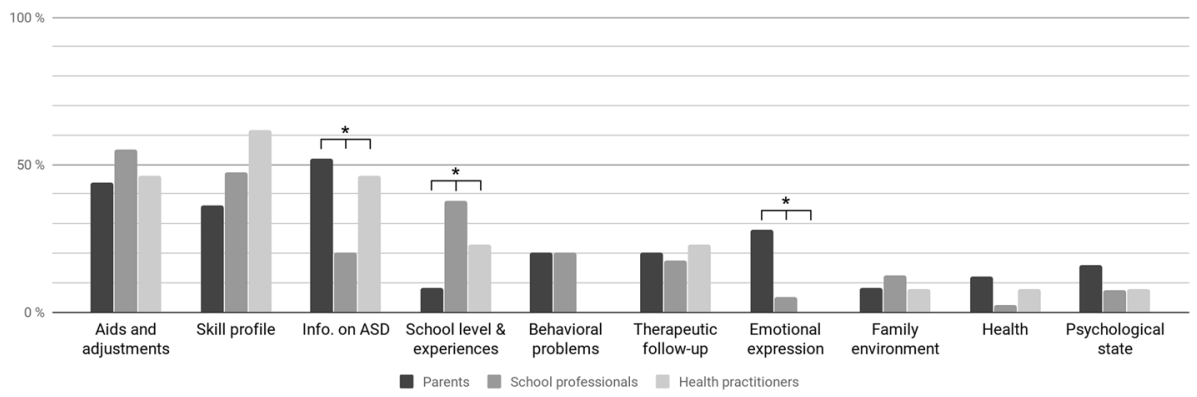

Fig. 4 Recurring themes reported in the open-ended question about the information needs, with the distribution between the three categories of respondents (family, school and health professionals) 
Table 2 Distribution of "Yes" answers to the close-ended questions according to the 13 themes proposed

\begin{tabular}{lllll}
\hline Question's theme & $\begin{array}{l}\text { School profes- } \\
\text { sionals }(\mathrm{N}=40)\end{array}$ & Parents (N=25) & $\begin{array}{l}\text { Health profes- } \\
\text { sionals (N=13) }\end{array}$ & Total (N=78) \\
\hline Aids and adjustments & $40(100 \%)$ & $23(92 \%)$ & $13(100 \%)$ & $76(97 \%)$ \\
Everyday functioning & $38(95 \%)$ & $24(96 \%)$ & $13(100 \%)$ & $75(96 \%)$ \\
Level of autonomy & $37(93 \%)$ & $24(96 \%)$ & $12(92 \%)$ & $73(94 \%)$ \\
External interveners & $38(95 \%)$ & $21(84 \%)$ & $13(100 \%)$ & $72(92 \%)$ \\
Social abilities & $34(85 \%)$ & $24(96 \%)$ & $13(100 \%)$ & $71(91 \%)$ \\
Verbal language level & $34(85 \%)$ & $23(92 \%)$ & $13(100 \%)$ & $70(90 \%)$ \\
Cognitive abilities & $34(85 \%)$ & $23(92 \%)$ & $13(100 \%)$ & $70(90 \%)$ \\
General information on ASD & $34(85 \%)$ & $22(88 \%)$ & $12(92 \%)$ & $68(87 \%)$ \\
Non-verbal communication & $34(85 \%)$ & $20(80 \%)$ & $13(100 \%)$ & $67(86 \%)$ \\
School level and experience & $31(78 \%)$ & $22(88 \%)$ & $11(85 \%)$ & $64(82 \%)$ \\
Language abilities & $27(68 \%)$ & $23(92 \%)$ & $13(100 \%)$ & $63(81 \%)$ \\
Health & $27(68 \%)$ & $21(84 \%)$ & $13(100 \%)$ & $61(78 \%)$ \\
Daily events & $26(65 \%)$ & $20(80 \%)$ & $13(100 \%)$ & $59(76 \%)$ \\
\hline
\end{tabular}

\section{Close-ended questions}

The internal consistency between the 13 close-ended questions was controlled using Cronbach's alpha, and revealed a satisfactory internal consistency $(\alpha=0.76 ; 95 \%$ CI [0.68; $0.83]$ ). For closed-ended questions, we observed that the 13 proposed themes were supported by at least $75 \%$ of the respondents as useful information domains (Table 2). This suggests that globally all respondents agreed on the usefulness of information across all the themes proposed. However, we noted that a smaller proportion of school professionals find information about daily events useful compared to health professionals (Fischer's exact test; $p<.05, \mathrm{~V}=0.297, \mathrm{RR}=0.65$ ). The comparison between the three respondents' categories does not show other significant differences on the proposed themes (Fisher's exact test; $p>.05$ ). Close-ended questions were completed with an open-ended question asking for precision on the information needed for each proposed domain. From those answers, we have extracted the main information domains required by the stakeholders (Table 3).

\section{Idea generation for designing the "ToGather" web app.}

From the collected data, we distinguished four main domains of consensual needs:

(1) A skill profile knowing strengths and weaknesses, cognitive capacities, and difficulties (e.g., memory, attention, executive functions). This domain of needs is related to the following themes: level of autonomy; intellectual and cognitive abilities; language abilities; and school level and experiences

(2) A profile of autistic particularities knowing perceptive, cognitive, and social atypicalities; routines and rituals; anxieties; talents. This domain of needs is related to the following themes: verbal and non-verbal communication; emotional and social skills; everyday functioning; and health and psychological state 
Table 3 Main information domains mentioned for each close-ended thematic question

\begin{tabular}{|c|c|}
\hline Level of autonomy & $\begin{array}{l}\text {-Autonomy in carrying out school work } \\
\text {-Ability to respond to change or failure } \\
\text {-Time and mobility management } \\
\text {-Autonomy in carrying out daily-living activities }\end{array}$ \\
\hline Language and verbal abilities & $\begin{array}{l}\text {-Language understanding } \\
\text {-Verbal expression } \\
\text {-Pragmatic use of the language } \\
\text {-Particularities in the use of language }\end{array}$ \\
\hline Cognitive abilities & $\begin{array}{l}\text {-Memory and attention } \\
\text {-Abstraction, imagination, creativity } \\
\text {-Planning, set shifting, problem-solving }\end{array}$ \\
\hline Non-verbal communication & $\begin{array}{l}\text {-Use of gaze } \\
\text {-Use of gestures and mimicking } \\
\text {-Understanding of gestures, mimics, postures, prosody, etc }\end{array}$ \\
\hline Social abilities & $\begin{array}{l}\text {-Ability to work in a group } \\
\text {-Knowledge of social rules } \\
\text {-Relational abilities } \\
\text {-Abnormal reactions and blockages }\end{array}$ \\
\hline Everyday functioning & $\begin{array}{l}\text {-Talents and areas of focus } \\
\text {-Fears and anxieties } \\
\text {-Cognitive and perceptual particularities } \\
\text {-Habits and routines } \\
\text {-Strengths and weaknesses } \\
\text {-Emotional signs and expressions (fatigue, stress, pain) }\end{array}$ \\
\hline School level and experiences & $\begin{array}{l}\text {-Level of written language } \\
\text {-Level in literacy and numeracy } \\
\text {-Previous school experiences } \\
\text {-School life }\end{array}$ \\
\hline General information on ASD & $\begin{array}{l}\text {-Definition of ASD } \\
\text {-Forms and symptoms } \\
\text {-Associated disabilities } \\
\text {-Therapies and interventions }\end{array}$ \\
\hline External interveners & $\begin{array}{l}\text {-Name, occupation and contact information } \\
\text {-Therapeutic curriculum (e.g., periodicity, objectives) } \\
\text {-Advices and follow-up }\end{array}$ \\
\hline Health & $\begin{array}{l}\text {-Chronic conditions or disease } \\
\text {-Sleep and food } \\
\text {-Treatments and possible side effects } \\
\text {-Comorbidities }\end{array}$ \\
\hline Daily events & $\begin{array}{l}\text {-Recent stressing events } \\
\text {-Relationships with peers } \\
\text {-Quality of sleep and health } \\
\text {-Occurrence of crises or behavioral problems }\end{array}$ \\
\hline Aids and adjustments & $\begin{array}{l}\text {-Performance aids } \\
\text {-Adjustment aids }\end{array}$ \\
\hline
\end{tabular}

-Autonomy in carrying out school work

-Ability to respond to change or failure

-Time and mobility management

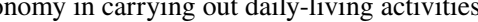

-Particularities in the use of language

-Planning, set shifting, problem-solving

-Use of gaze

-Use of gestures and mimicking

-Understanding of gestures, mimics, postures, prosody, etc

-Ability to work in a group

-Talents and areas of focus

-Fears and anxieties

-Cognitive and perceptual particularities

(a)esses

ss, pain

-Level in literacy and numeracy

-Previous school experiences

-School life

-Therapies and interventions

(e.g., periodicity, objectives)

-Sleep and food

-Treatments and possible side effects

-Comorbidities

-Relationships with peer

-Quality of sleep and health

-Performance aids

(3) A help profile knowing effective supports and coping strategies for an individual's performance and better adaptation. This domain of needs is related to the aids and adjustments themes and is related to the child's profile and capabilities.

(4) General information knowing information about ASD and its manifestations, about the student's health state, about external partners who follow him/her, about the school 


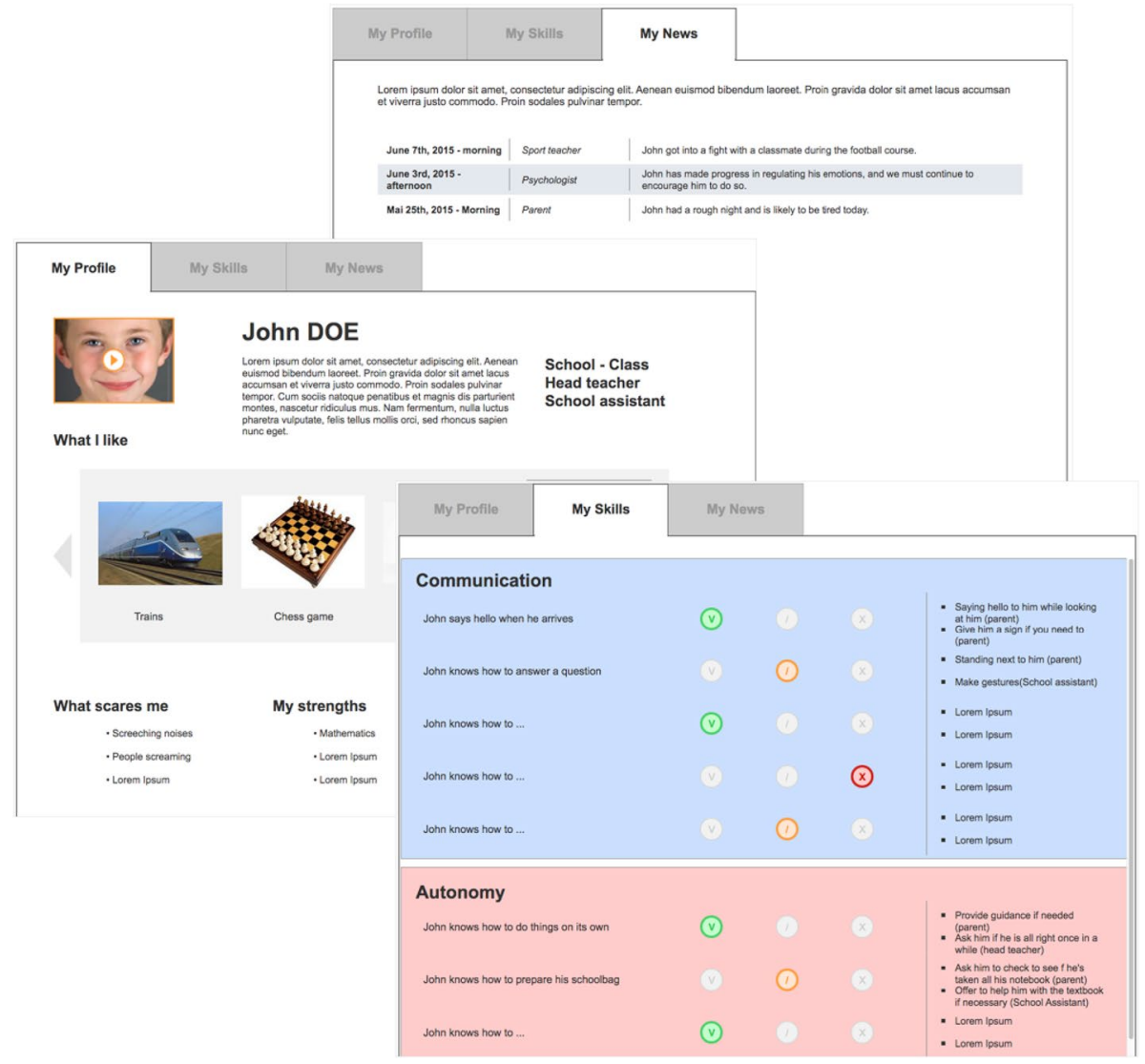

Fig. 5 The first mock-up of the "ToGather" app

experience, as well as about the recent daily events. This domain of needs is related to the following themes: information on ASD; family and external interveners; and daily events.

Next, we designed an initial prototype of a "ToGather" app for information sharing, communication, and coordination between the stakeholders from different settings. The structure of the prototype was developed based on the four main domains listed above (Fig. 5, from left to right):

(1) The "My Profile" section contains information about the student's particularities and general information about his/her care and support and his/her school experience. This section gathers the domain of needs regarding the specificity of the child's profile, as well as parts of the skill profile.

(2) The "My Skills" section proposes an evaluation grid, in which skills are classified according to several categories. In each category, several items can be rated for assessing the student's skill level. For each item, a form allows precise corresponding effec- 
tive aides and adjustments. This section is related to the domain of needs related to the skill and the help profiles.

(3) The "My News" section allows to share information in the manner of a home-school's liaison diary and to easily exchange various information daily. This section is related to the need for general information.

The main concept of the tool is to provide a digital student record that allows information to be searched, skills to be assessed and monitored, and important information to be communicated. Every user will be identified according to their role (e.g., teachers, parents) to access only the data that concerns them. We opted for the development of a web-based tool to ensure easy cross-platform access for all different stakeholders. Indeed, a website has the advantage of being accessible via a browser, regardless of the digital medium used (e.g., computer, tablet, smartphone) and the location of the person. This point is important because stakeholders from each setting (i.e., family, school, medico-social) do not meet frequently and may be geographically distant (e.g., in the case of a boarding school).

\section{Iterative prototyping of the "ToGather" app.}

\section{Method}

\section{Participants}

We recruited a panel composed of target stakeholders to participate in the design of the tool and to collect feedback on the first mockup of the "ToGather" app. This panel included: four health professionals (i.e., two child psychiatrists specialized in ASD, an occupational therapist, and a psychologist); four school professionals (i.e., a national education inspector, an officer for professional insertion, a specialized teacher, and a lead officer of accessibility services), and two parents of children with ASD, who were also parent representative in a non-profit organization for individuals with ASD.

\section{Procedure}

The iterative prototyping process consisted of alternating design stages and end-user feedback. Thus, we have arranged two meetings, interspersed with two phases of feedback integration in the prototype.

The first iteration included a meeting of about $2 \mathrm{~h}$ with two health professionals, and then with two school professionals. During these meetings, we introduced the general project and our work objectives. Then, we presented the prototype and its functionalities. Once this presentation was completed, we answered their questions and collected their feedback about the prototype.

For the second iteration, we arranged a 2-h meeting with our entire panel to present the new model of the tool in the presence of the design team. After a demonstration of the tool, there was a time for interactions between professionals, parents, and the app designers to reflect on possible ways to improve the design. Throughout the meeting, we took note of the exchanges that took place to produce a summary report. 


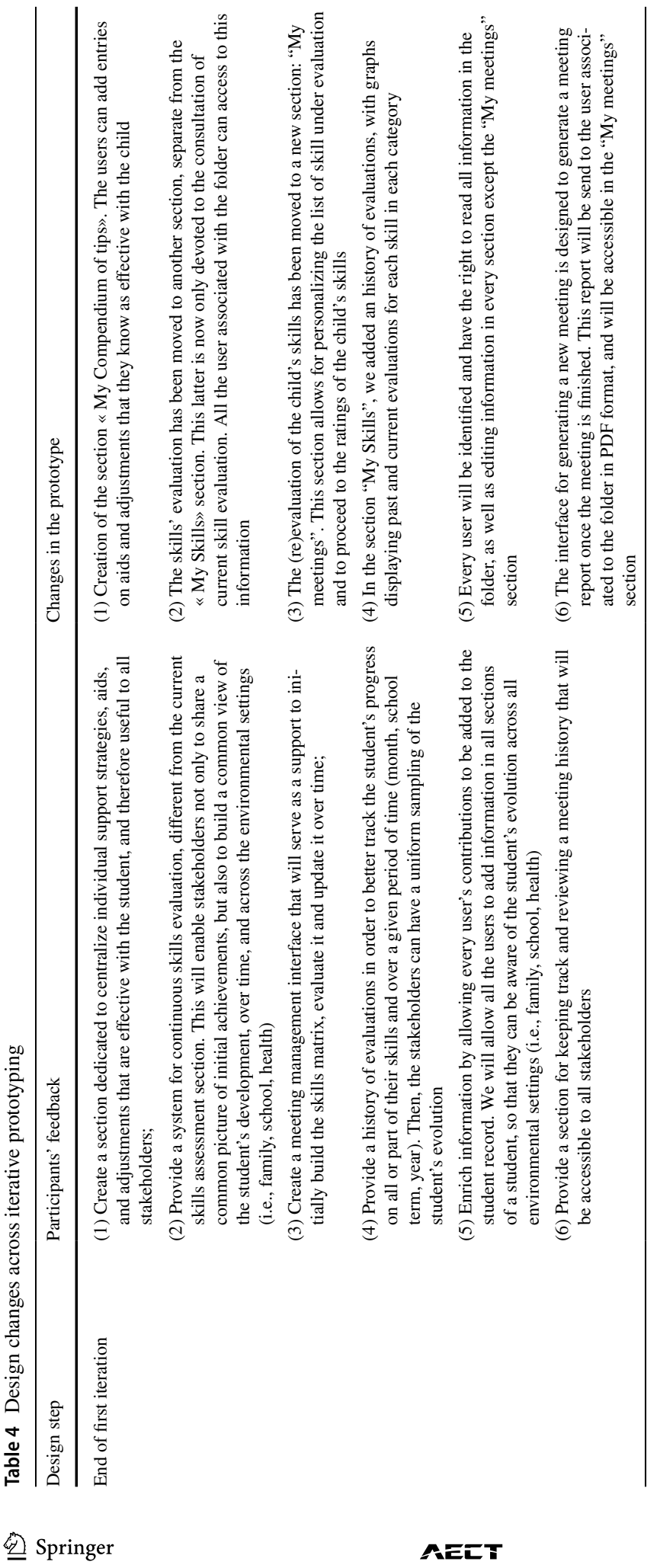




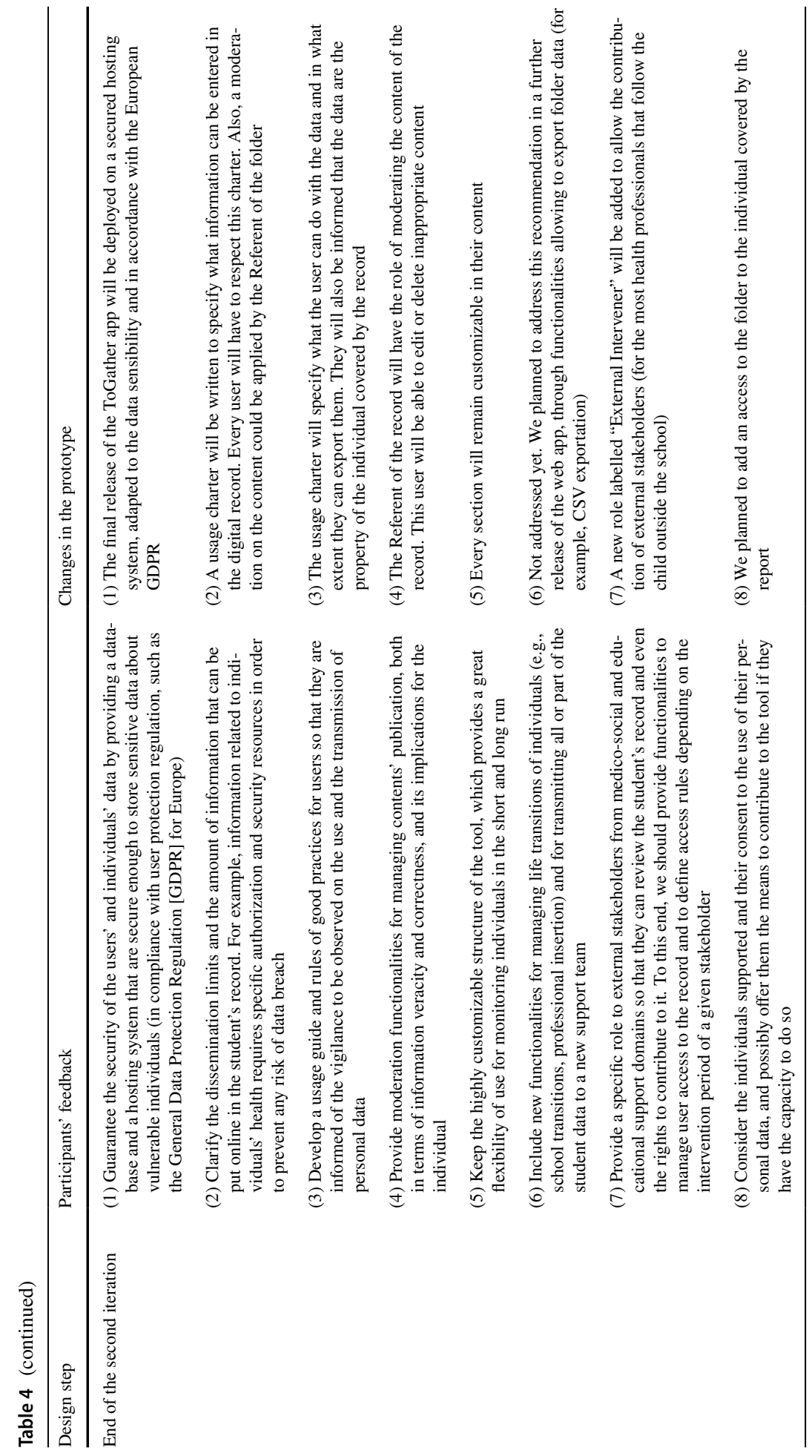




\section{Results}

At every iteration, the feedback from the participants has been summarized through a list of specifications for the next version. These specifications have been linked to changes in the prototype throughout the iterative design. This information is reported in Table 4 .

\section{Participants' feedback at the end of the first iteration.}

The first discussions with the professional stakeholders allowed us to develop our model concerning the actual practices and needs of parents and professionals. Once analyzed, the feedback from the participants has been summarized through a list of specifications for the next version (see Online Appendix 2).

Rather than listing aids and strategies in the "My Skills" section, the professionals suggested creating a fully separated section, dedicated to the support strategies that are effective with the student: a "compendium of tips". This type of compendium is already part of the practices used with students with ASD to keep track of useful and effective aids and adaptations. Such a compendium would make it possible to capitalize on the efforts and knowledge of family and professional stakeholders and to facilitate transitions (e.g., new professionals, new classes, new school).

A reflection was initiated on the way to assess the students' skills. In the current version of the "ToGather" app, skills can be re-evaluated directly from the "My Skills" section. This approach may cause problems if all users can change the skill assessments at any time. Also, the original design did not include a history of skill assessments, which would allow for a long-term follow-up of the student's skills. This critical aspect was emphasized by all the stakeholders involved in the support of students with disabilities or special needs.

Finally, another weakness of the prototype was the purpose of information sharing. As it stands, the app provides fixed information, which can be reviewed by each user: the app was not designed to share information that can be dynamically enriched by the stakeholders. As the objective of the tool is to promote collaboration between the stakeholders to support the student's inclusion, we needed to develop functionalities that would foster information sharing and discussion between them. To this end, we added a section for managing follow-up meetings, which is used as support to complete and update the student's skill assessment.

\section{Second release of the "ToGather" app}

We revised the design of the "ToGather" prototype based on the participants' feedback and produced a second version. The three main sections remained but their functionalities were updated. Two sections were added to follow the professionals' recommendations. The tool is now fully customizable and provides a structure for gathering information so that users can define the contents they wish to include depending on the individuals they support.

Once the user is logged in, they access an interface to select the student they want to review (Fig. 6). This interface displays the list of students they support. When the user selects a student, they can consult the information about parents, the record's referent, and access to the student record.

The student record is now composed of five sections: 


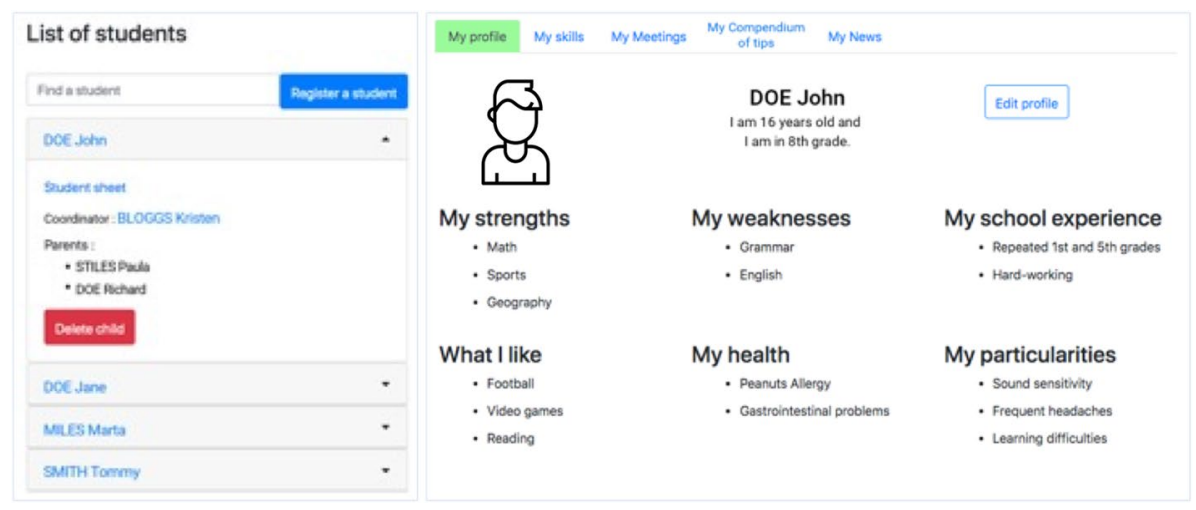

Fig. 6 The web interface of the designed tool. Left: the page for accessing to students' records. Right: the first page of the record, with the content of "My Profile" section

(1) "My Profile" (Fig. 6) This section has been designed as an identity card of the student and its particularities. The content is fully customizable to be adaptable to all types of student profiles. All users can contribute to the profile by adding, editing, or deleting items or categories of items. The profile section is composed of several fully customizable bullet lists displaying general information about the student profile and specificities (e.g., strengths, weaknesses, fears, talents). This structure gives a global picture of the student allowing the user to easily and quickly review the main information on the student.

(2) "My Skills" (Fig. 7) This section still offers a matrix for skills assessment, but its structure has been fully revised. To improve its readability, the skills are classified into categories, corresponding to school-related and socio-adaptive skills frame of reference, materialized by tabs (e.g., communication, autonomy, numeracy, literacy). Each skill category is composed with:

- A matrix displaying current evaluation of student's skills (Fig. 7, left): for an organized view on current objectives, the skills of each category are classified into three sections: "current skills" (i.e., skills currently in training), "acquired skills"” (i.e., newly acquired skills, which may be subject to regression), and "archived skills" (i.e., consolidated skills with consistent proficiency). For each skill item, three-level graduation is provided to rate the mastery level: "trainee", "proficient", and "consistently proficient".

- A history of student skill evaluation displayed on a graph (Fig. 7, right): Progress in each skill of the category is visualized with different colored lines depending on past and current evaluation data. It is possible to select a range of skills to be displayed and the period to consider.

(3) "My Meetings" (Fig. 8) This new section has been created to offer both an interface dedicated to the building of the evaluation matrix and the skills assessment, as well as functionalities allowing to generate meeting reports and to keep a meeting history. This section is composed with:

- A list of previous meetings, with clickable links to download the reports in PDF format. 


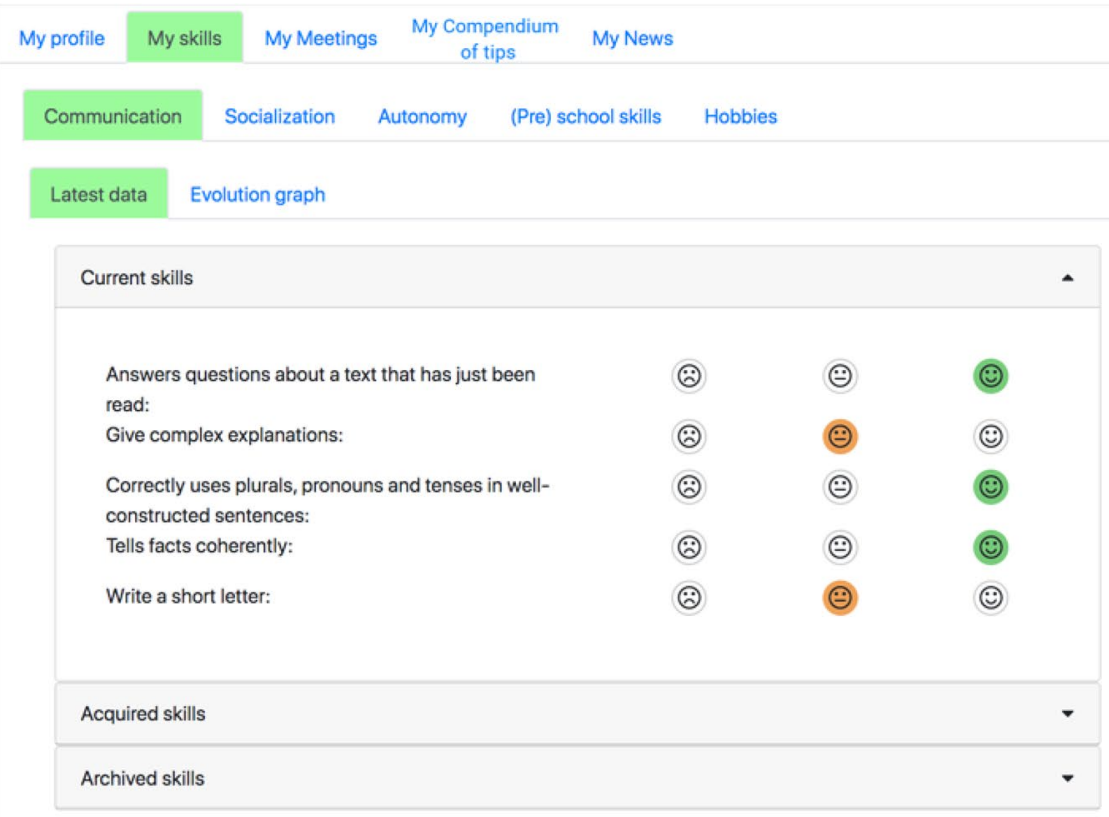

\section{Latest data Evolution graph}

\section{- Number of values per skill 4

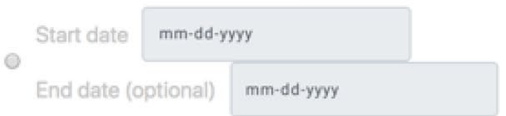 \\ $\checkmark$ Current skills $\square$ Acquired skills $\square$ Archived skills}

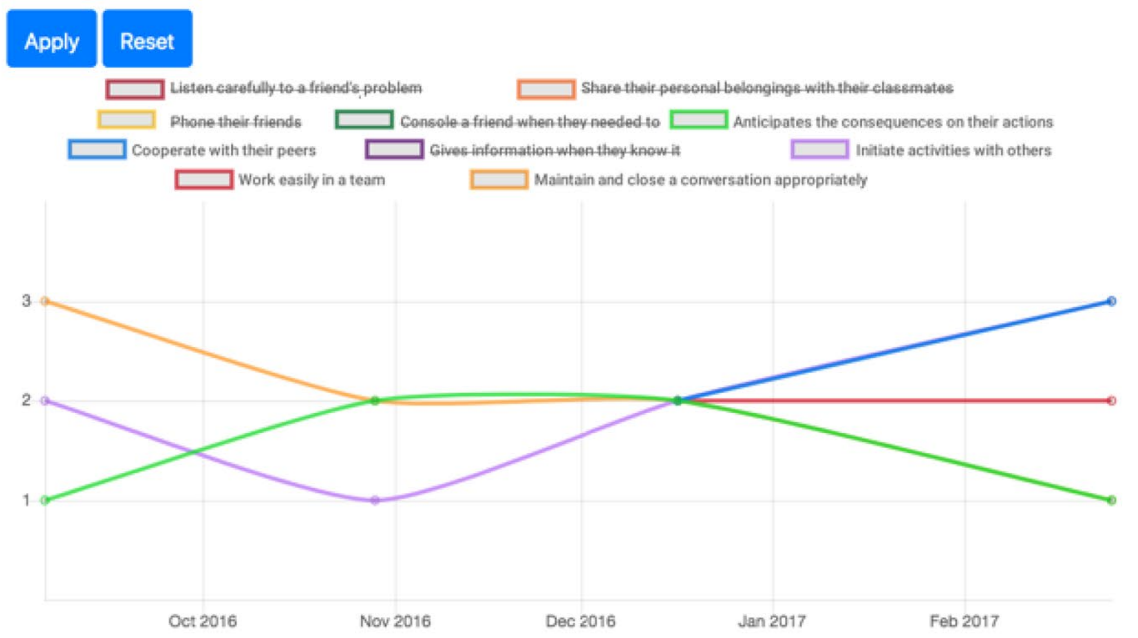

Fig. 7 The interface of the "My Skills" section, allowing to consult student's skill assessment per category. This section proposes both current skill evaluation (left) and a progress graph with actual and past data (right) 


\begin{tabular}{|l|l|}
\hline My profile My skills $\quad$ My Meetings & $\begin{array}{c}\text { My Compendium } \\
\text { of tips }\end{array}$ \\
\hline Meeting history & New meeting \\
\hline Informations \\
\hline Meeting of $10-25-2018$ \\
\hline Meeting of $06-12-2018$ \\
\hline Meeting of $02-15-2018$ \\
\hline Meeting of $11-21-2017$ \\
\hline
\end{tabular}

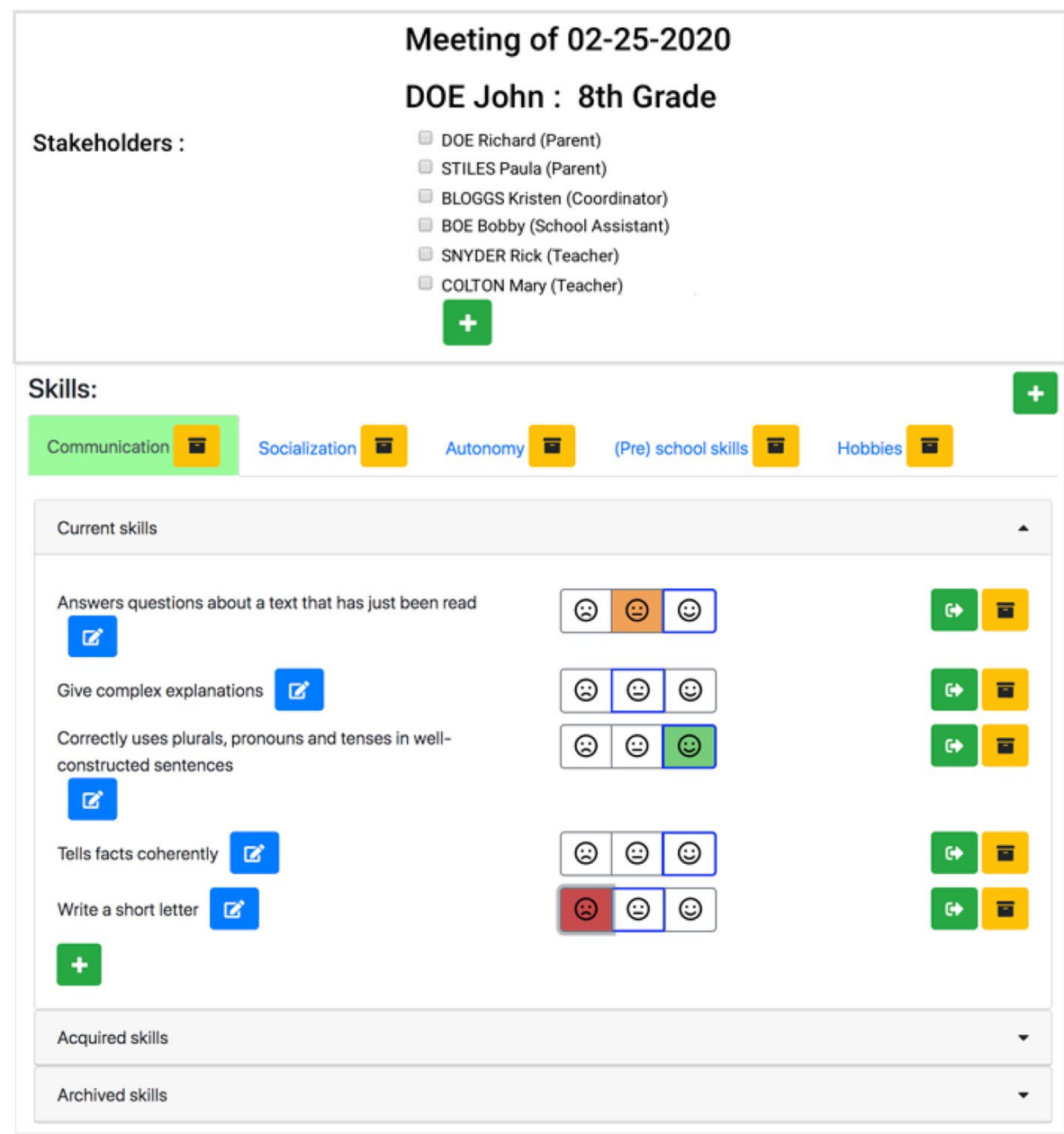

Fig. 8 Top-left: the interface of "My Meetings" section, with the history of past meetings and links to download the PDF report. Bottom-left: the header of the meeting creation interface allowing to select the recipients of the report. Right: the interface for (re-)evaluate the student's skills and manage the list of skills 

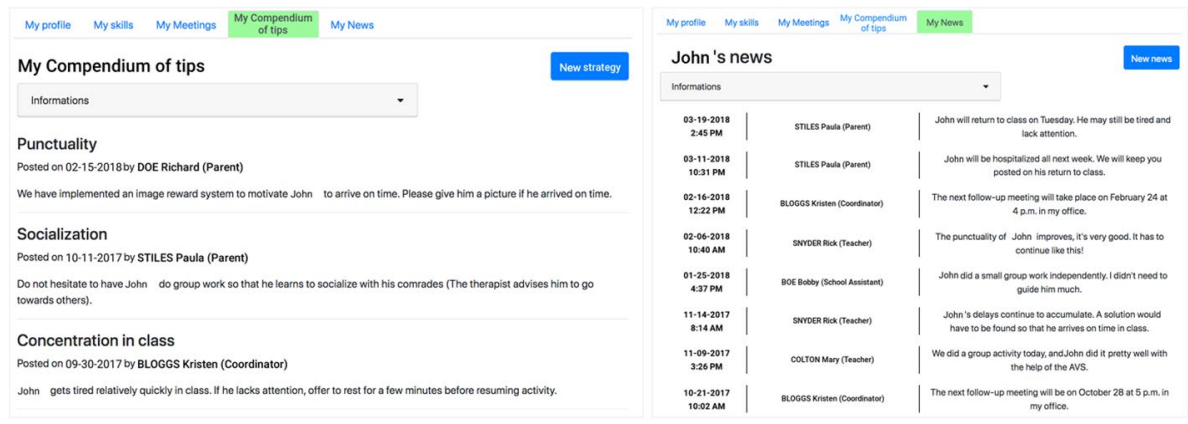

Fig. 9 Interfaces for the sections "My Compendium of tips" (left) and "My News" (right)

- A link to the interface for creating a new meeting to manage skills and their evaluation, and to generate a meeting report that can be sent to the users associated with the student record.

The interface for creating new meetings opens in a new window (Figure 8). The header displays the list of users associated with the student record and allows to select users that will receive the meeting report. Users can also add the email address of additional recipients manually. Below, the interface displays a grid containing all the skills by category, identical to what is proposed in the "My Skills" section. For each skill, the current evaluation is displayed and the users can simply click on a new value to change it. The categories and the skills are fully customizable: the users can add, edit and delete skill items and categories. Also, each skill can be qualified as being acquired or archived, depending on whether or not they are the subject of the student's current objectives. Finally, a box allows users to enter comments and will be included in the logs of interactions concerning the skills (for example, "skill $X$ has been archived").

Once the meeting is validated, a report is generated in PDF format and sent to all recipients designated in the header. The report is then available in the meeting history.

(4) "My Compendium of tips" (Fig. 9, left) this section indexes all strategies, aids, and adjustments known to be effective for the student. All users can consult and enrich this compendium, and contribute to the knowledge base of student functioning. Users can consult the list of strategies, aides, and adjustments, which allow them to carry out activities with the student.

(5) "My News" (Fig. 9, right) this section implements a communication channel for transmitting timely information about past, current, or future events. As in a home school diary, this section also allows transmitting messages to other users associated with the student's record. 


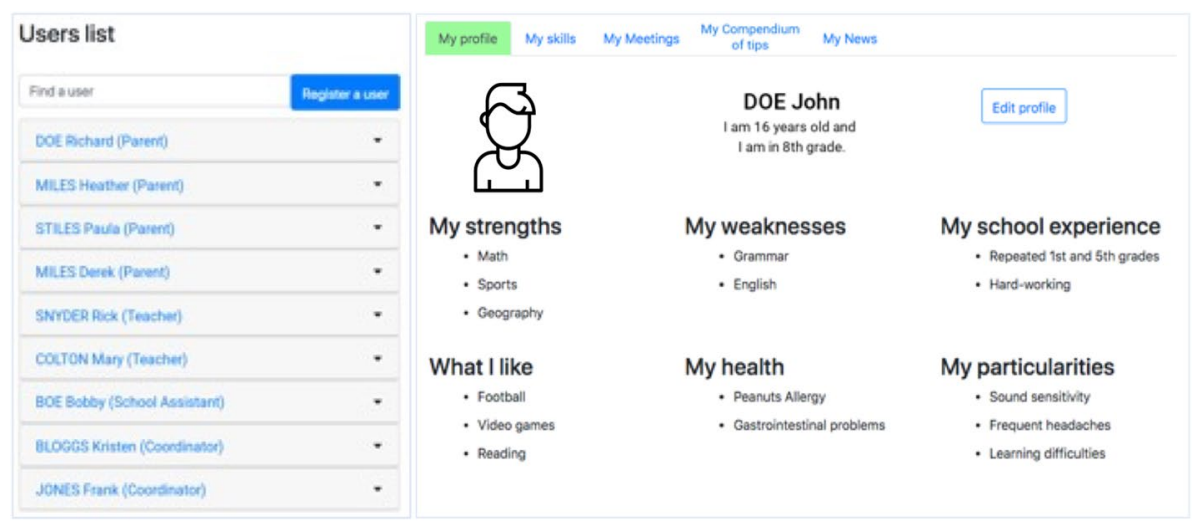

Fig. 10 Left the users list and their respective roles (page available for the administrator). Right the final prototype with the five sections

\section{Participants' feedback at the end of the second iteration.}

The new prototype has been tested with the entire panel of potential end-users. Again, the feedback from the participants has been summarized through a list of specifications for the next version (Table 4). Their feedback can be classified in two categories:

1. Design-related feedback about functionalities and their usefulness in the various professional practices (e.g., how to scale skill evaluation, how to add or edit information).

2. General feedback about roles and status of each stakeholder, user rights, as well as data security.

The first point of discussion raised by the panel was about data access and security. People with disabilities, especially children, are considered vulnerable by French regulation: their personal data are deemed sensitive. It is thus of utmost importance to ensure a maximal level of security in storing and accessing the students' personal data.

A second important point was raised about the moderation of contents published in the student record. Participants wondered how the record content could be moderated to avoid problems related to misinformation or disclosing information to inappropriate users.

A third point raised the issue of allowing external professionals (medico-social and educational) to access students' information via the app when they were conducting long-term interventions. Children with ASD are often under professionals' care (health and/or educational); including them as temporary users may allow the student record to be enriched with information and tips from ASD specialists. This is even more relevant given that the level of ASD-specific training in families and school professionals remains relatively low. The panel envisaged to include these professionals and to give them their role in the app, even though they found it necessary to be able to manage their access rights over time (e.g., define a period during which the user has access to the record).

Throughout the meeting, a deeper reflection related to data ethics and deontology was initiated about the kind of information about individuals that can be put online and the users that can review it. The professionals stressed the need to be vigilant in clearly defining the type of information that can be included in the app, and who can review it. Also, 
they emphasized the need to consider the consent of individuals or their legal representatives before collecting and sharing data about them.

\section{Third release of the "ToGather" app.}

Based on the above feedback, we pursued the design of the tool and developed user authentication methods. Each user is identified depending on a role, which allows users to be assigned access rights depending on their relationship to the student: e.g., parents, teachers, school aides (Fig. 10). For example, parents can only access their child's record, teachers their students' records, and health practitioners the children they support.

We also created the "Referent" role, defined as the person in charge of the regular monitoring of a student's record. The referent has a particular role in the app in that they are the only ones who can create new meetings, and who have access to the skill evaluation and grid edition. The referent role does not designate a particular occupation, but formalizes a coordination role in the support team; it refers to primary contact for issues related to the support and the monitoring of a student. This role of "Referent" can be assigned to any professional of the support team. For example, the "Referent" can be an educator, a teacher, or someone who follows the student regularly to be able to coordinate assessment and follow-up meetings.

Finally, an administrator will be appointed for each school to manage the creation of users and student records, as well as users' rights to access those records. Concerning the management of information flow added in each record, we have integrated content moderation functionalities for allowing the referent to manage information published in the record.

\section{Discussion}

This design study aimed at developing a novel tool for supporting school inclusion of students with ASD by specifically addressing the relationships between their familial and professional caregivers.

The needs analysis conducted with inclusive education stakeholders provided us information on the points of consensus and divergence among family, school, and medico-social stakeholders regarding their needs for supporting a student with ASD included in mainstream settings. All stakeholders agreed on the importance of having information on skills and particularities and also sharing information about individual effective strategies, aids, and adjustments. However, we also observed disagreements between the three kinds of informants, and notably between parents and school professionals. The stakeholders from the three settings share central needs related to the minimal information needed for better supporting the students with ASD, but there are also points of divergence on how to prioritize student information. Such a result is in accordance with ASD studies revealing parentteacher tensions (e.g., Azad \& Mandell, 2016; Azad et al., 2018; Bezdek et al., 2010; Kurth et al., 2019; Schultz, et al., 2016; Tucker \& Schwartz, 2013).

Thanks to the user-centered iterative design method, the prototype of an assistive tool for inclusive education stakeholders was enriched with best practices gathered from professionals. For example, the section "My Compendium of tips" was directly inspired by a paper-and-pencil field practice to record all effective strategies with the student. Such a 
digitalization of paper-pencil practice is a successful way to facilitate technology adoption by end-users (Fage et al., 2019).

We hypothesized that the long-term use of this tool is likely to increase team cohesion and coordination for the benefit of the student. Indeed, the objectives and functionalities of the final prototype are in line with the elements highlighted in the Delphi study of Gomes and McVilly (2019):

1. A shared focus on patient outcomes The skill evaluation matrix displays organized information depending on semantic categories of skills and objectives (i.e., trainee, proficient, consistently proficient). The tool provides child-centered information on both the current skill evaluation and its history with a customizable graphical display for an easy visualizing of the progress over time. Hence, all users can have a representation of the students, which in turn may help them to adjust their practices.

2. Good communication among the team Two sections of the tool are dedicated to the communication between users. Permanent information regarding support strategies is separate from temporary information related to daily events. The compendium of tips allows caregivers to populate an index of all effective aides and adjustments, and to provide access to all stakeholders of the support team. Also, the functionalities for generating and sending meetings' reports facilitate the sharing of information related to decisions and discussions on IEP and the way to support the student and allow to keep track of interactions.

3. An effective leadership Designating a coordinator role for each student record allows formalizing a coordination position in the student support team. Given the number of individuals involved in the student's follow-up, it is essential to designate a "resource" person in charge of the coordination of the team's actions and for the organization of the student's follow-up.

Nevertheless, the iterative design process of this digital tool raised questions and reflections about teamwork that can be compared with issues raised in the literature. The involvement of families and individuals in the building and the implementation of the IEP is highly recommended for quality support (e.g., May et al., 2019). When using the app, the parents have the same rights to review and edit information as the other users. This may encourage parents' contributions to the student's record and allow them to express their point of view. However, in practice, it is often difficult for professionals to give parents an equivalent role in the team (e.g., May et al., 2019; Kurth et al., 2019; Schultz et al., 2016; Tucker \& Schwarz, 2013). Giving all users the same access rights allow to place them on equal terms. This may, in turn, foster more active participation of parents in the IEP and their child's school life. The panel of participants has also discussed the feasibility of creating a role for the students themselves. For example, consulting and discussing the latest skill evaluation with the student may improve their self-evaluation and regulation skills. Envisaging a role for the individual with ASD in the app would also allow to involve them in the building, the implementation and the update of their support, as recommended (May et al., 2019).

Participants discussed the possibility to give a role in the app to external medicosocial and education professionals. The latter can be key partners in the support process, as they represent a critical source of information related to the children and their profile. Those professionals can access all available information about the child over time, which in turn, could provide them with essential information to improve their 
interventions. However, the participants were also concerned about the sensitivity of some information because of the differences of perspectives between settings and disciplines (e.g., capacity vs. deficiency view of the disability). In summary, the inclusion of external interveners in the tool is welcomed by the panel, but only if the tool allows access to students' information to vary with respect to the roles. These reflections are related to the issue of interprofessional relationships in the context of teamwork, which can be strained because of opinion divergences or the use of discipline-specific vocabulary (Bernie et al., 2019; Long et al., 2017).

Finally, although our primary objective was to address the particular situation of students with ASD in middle and high schools, the entire panel has recognized the crossdisabilities value of the tool for supporting individuals with disabilities throughout their school curriculum. Indeed, the professionals of the panel come from different backgrounds and work with both children and adults. They have all appreciated the fact that the tool is fully customizable in terms of content; they perceived the tool as applicable to children with other disabilities and adults as well. The participants also found a great interest in the tool during life transitions, where they are at high risks of information loss when a change in the team occurs. As teams can change during life transitions, the tool can allow transmitting important information to keep about the individuals from one team to another.

During the iterative process, the participants discussed fewer issues related to the interface and the functionalities, compared with questions related to information access and users' rights. In other words, this design process elicited more questioning about ethics, deontology, and social organization in field practices, rather than ergonomic and functional features of the prototype. These questions may be related to field problems encountered by family and professional caregivers of a child included in mainstream settings. For example, defining which stakeholder can review and edit the record relates to the problems in defining each stakeholder's responsibility and legitimacy in the individual's follow-up and support in existing practices: who is to coordinate the IEP? Who is to provide specific information or assessments? Although multidisciplinary follow-up and support, as well as promotion of self-determination, are highly recommended by WHO and UNICEF, no precise team building is recommended and no particular role is formally defined. Therefore, the coordination of the support process is done on a case-by-case basis, according to the configuration of individuals' living settings. This can contribute to tensions and misunderstandings between the stakeholders, and in turn affect the quality of the relationships, eventually impacting the quality of support provided to the student. Designating a coordinator among the support team would provide leadership, but may also be controversial with regards to the role of each person.

By leveraging both the ICF-CY and the ecosystemic framework, this design study offers an original contribution in the field of technological solutions to foster the school inclusion of children with ASD. The originality key is to move forward this research field from an individual agentivity view to a collective agentivity view, where both the individuals and their social environment are co-responsible and then active co-builders of an inclusive school. Accordingly, the disability is then not the only matter of the disabled person or lawmakers, but their social environment as well, which provides proximal and distal support across everyday life settings. For the while, however, in the field of technology-related participatory design for people with special needs, approaches which stress and address the role of the social environment remain scarce, while individual-centered approaches are more prevalent (e.g., Frauenberger et al., 2011; Robb, et al., 2021). This latter focuses on 
the triangulation of the individual needs in relation to the activity and the support tool and relegates the environment to a contextual factor.

Additionally, the ecosystemic model can be seen as a new venue for extending the powerfulness of the participatory design framework from an individual to a collective agentivity view. As one of the primary assets of participatory design is individual empowerment through decision-making in design, it can be expected that its application with a collective agentivity view will strengthen the social environment at the individual and collective scale. The rationale of this expectation is grounded on the extensive work on the self-determination theory (Ryan \& Deci, 2020), indicating that all intrinsically motivated decision-making leads to the individual being more engaged, more effective, more confident, and more fulfilled in their chosen activities. Furthermore, the self-determined decisions are reported socially synergic, particularly in educational settings where "a dynamic link between teacher and student motivation", as teachers are themselves forced to find ways to support students' needs despite organizational and institutional obstacles (mandated curricula, controlling performance pressures, and leadership styles) (Ryan \& Deci, 2020). In this study, participants expressed a real enthusiasm for this research project, which can be partly explained by empowerment linked to the feeling of having their needs heard and the opportunity to contribute to change things. As a result, the participants were willing to step out of their social and institutional roles to consider the transformations needed to achieve a more inclusive ecosystem. The ToGather prototype, which emerges from this process, is only the formalization of this transformation. Even if they diverge on some of their needs, every stakeholder was willing to make concessions to achieve consensus, sacrificing individual leadership for the sake of collectively positive change.

The emphasis on the collective agentivity echoes with participatory or citizen science purposes where the citizen or collective voice are expected as accelerators of societal changes, which may result in changes in public policies, as well as in attitudes and social representations (National Academies of Sciences, Engineering, and Medicine, 2018). Indeed, embedding a collective agentivity view into participatory design methods may strongly support a bottom-up approach of science, rather than a top-down one that is "unitary and prescriptive" (Lengwiler, 2008). Due to its problem-centered nature, this approach is fruitful for both researchers and participants by producing science progress and societal innovation such as depth changes of practices of everyone (student, families, school, community) while helping bridge the theory-practice gap. Institutions advocate comprehensive communication and collaboration in IEP teams, but few of them provide practical tools that may enable these practices. Through the citizens' participation, the problems and needs that the social environment encounters in the field can be easier emerged, transformed into a co-decided solution, and then led to institutions to formalize it for a sustainable change. The ToGather app will not alone change the deal, but it will provide support to people, who have the potential to elicit changes in societal dynamics by their collective practices.

\section{Conclusion and perspectives}

This study aimed to design a digital tool for addressing socio-environmental obstacles to the school inclusion of students with ASD in mainstream settings. Combining both ecosystemic approaches and the ICF framework allowed us to identify a relevant intervention target for improving the care and support of children with ASD, that is, the relationships between family, school, and medico-social settings involved in the support process. Future 
studies should consider addressing more deeply the socio-environmental barriers which impede school inclusion to provide new support tools for inclusive education stakeholders.

The design of the "ToGather" app was based on a user-centered methodology involving participatory aspects, beginning with an analysis of the information needs of family and professional caregivers of a student with ASD included in mainstream school. This phase allowed us to develop a first version of the tool, which was tested against the panel, for identifying several ways to deepen the design of the structure and the contents of the app. This design process also elicited reflections about the tool's integration in actual support practices and the possible impact related to its use. However, the sample size was limited, and professional settings were more represented than family ones. Future work will pursue the development of the "ToGather" app, with a larger panel of potential users. This will allow conducting a usability evaluation as well as a field study for the evaluation of the usefulness and the ergonomic qualities as well as the effectiveness of the "ToGather" app in supporting parents, teachers, and professional caregivers, as well as the interactions between the three settings (i.e., family, school, medico-social). This future study may highlight whether the "ToGather" app may or not improve the quality of support provided to students with ASD included in mainstream schools.

The final prototype generated great interest among family and professional caregivers who have recognized its usefulness and transversal nature in supporting students with ASD, and more broadly, individuals with disabilities. However, this design process also stressed the difficulties they experience in their daily practice when it comes to coordinating efforts of each one to build a successful support project. More than simply proposing a digital student's record, the design of the app questioned socio-organizational issues related to the building and the implementation of an IEP for students with ASD, such as the role of each category of stakeholders and their contribution to the support project.

Supplementary Information The online version contains supplementary material available at https://doi. org/10.1007/s11423-021-10073-w.

Acknowledgements We would like to acknowledge Cécile Magnier for her work on the first mockup of the web tool and her contribution in the idea generation, as well as Benjamin Haté and the students from Enseirb-Matmeca at Bordeaux INP for their contribution to the development of the successive versions of the ToGather tool. We also gratefully acknowledge the families and the professionals who contributed to this work by participating either to the need analysis or to the focus group during the iterative design.

Funding Funding was provided by Fondation Orange (FR) and Inria Centre de recherche (FR).

\section{Declarations}

Conflict of interest The authors declare that they have no conflict of interest.

\section{References}

Allenbach, M., Duchesne, H., Gremion, L., \& Leblanc, M. (2016). Le défi de la collaboration entre enseignants et autres intervenants dans l'école inclusive : Croisement des regards. Revue Des Sciences De L'éducation, 42(1), 86-121. https://doi.org/10.7202/1036895ar

American Psychiatric Association [APA]. (2013). Diagnostic and statistical manual of mental disorders (5th ed.). American Psychiatric Association.

Azad, G., \& Mandell, D. S. (2016). Concerns of parents and teachers of children with autism in elementary school. Autism, 20(4), 435-441. https://doi.org/10.1177/1362361315588199 
Azad, G. F., Kim, M., Marcus, S. C., Sheridan, S. M., \& Mandell, D. S. (2016). Parent-teacher communication about children with autism spectrum disorder: An examination of collaborative problem-solving. Psychology in the Schools, 53(10), 1071-1084. https://doi.org/10.1002/pits.21976

Azad, G. F., Marcus, S. C., Sheridan, S. M., \& Mandell, D. S. (2018). Partners in school: An innovative parent-teacher consultation model for children with autism spectrum disorder. Journal of Educational and Psychological Consultation, 28(4), 460-486. https://doi.org/10.1080/10474412.2018.1431550

Bearss, K., Burrell, T. L., Stewart, L., \& Scahill, L. (2015). Parent training in autism spectrum disorder: What's in a name? Clinical Child and Family Psychology Review, 18(2), 170-182. https://doi.org/10. 1007/s10567-015-0179-5

Bernie, C., Sutherland, R., Williams, K., Marty, S., May, T., \& Roberts, J. M. (2019). Autism health and education: Professional roles and challenges. In R. Jordan, J. M. Roberts, \& K. Hume (Eds.), The SAGE handbook of autism and education (pp. 340-350). SAGE Publications Ltd.

Bezdek, J., Summers, J. A., \& Turnbull, A. (2010). Professionals' attitudes on partnering with families of children and youth with disabilities. Education and Training in Autism and Developmental Disabilities, 45, 356-365.

Bjögvinsson, E., Ehn, P., \& Hillgren, P.-A. (2012). Design things and design thinking: Contemporary participatory design challenges. Design Issues, 28(3), 101-116. https://doi.org/10.1162/DESI_a_ 00165

Bronfenbrenner, U. (1977). Toward an experimental ecology of human development. American Psychologist, 32(7), 513-531. https://doi.org/10.1037/0003-066X.32.7.513

Bronfenbrenner, U. (1979). The ecology of human development: Experiments by nature and design. Harvard University Press.

Bronfenbrenner, U. (2005). Making human beings human: Bioecological perspectives of human development. Sage.

Cappé, É., \& Boujut, É. (2016). L'approche écosystémique pour une meilleure compréhension des défis de l'inclusion scolaire des élèves ayant un trouble du spectre de l'autisme. ANAE : Approche Neuropsychologique Des Apprentissages chez L'enfant, 143, 391-401.

Catagnus, R. M., \& Hantula, D. A. (2011). The Virtual Individual Education Plan (IEP) Team: Using online collaboration to develop a behavior intervention plan. International Journal of e-Collaboration (IJeC), 7(1), 30-46. https://doi.org/10.4018/jec.2011010103

Chamak, B., \& Bonniau, B. (2016). Trajectories, long-term outcomes and family experiences of 76 adults with autism spectrum disorder. Journal of Autism and Developmental Disorders, 46(3), 1084-1095. https://doi.org/10.1007/s10803-015-2656-6

Corralejo, S. M., \& Rodriguez, M. M. D. (2018). Technology in parenting programs: A systematic review of existing interventions. Journal of Child and Family Studies, 27(9), 2717-2731. https:// doi.org/10.1007/s10826-018-1117-1

Design-Based Research Collective. (2003). Design-based research: An emerging paradigm for educational inquiry. Educational Researcher, 32(1), 5-8.

Edelson, D. C. (2002). Design research: What we learn when we engage in design. Journal of the Learning Sciences, 11(1), 105-121. https://doi.org/10.1207/S15327809JLS1101_4

Fage, C., Consel, C., Etchegoyhen, K., Amestoy, A., Bouvard, M., Mazon, C., \& Sauzéon, H. (2019). An emotion regulation app for school inclusion of children with ASD: Design principles and evaluation. Computers \& Education, 131, 1-21. https://doi.org/10.1016/j.compedu.2018.12.003

Frauenberger, C., Good, J., \& Keay-Bright, W. (2011). Designing technology for children with special needs: Bridging perspectives through participatory design. CoDesign, 7(1), 1-28. https://doi.org/ 10.1080/15710882.2011.587013

Freitag, S., \& Dunsmuir, S. (2015). The inclusion of children with ASD: Using the theory of planned behaviour as a theoretical framework to explore peer attitudes. International Journal of Disability, Development and Education, 62(4), 405-421. https://doi.org/10.1080/1034912X.2015.1046818

Gomes, M. F., \& McVilly, K. R. (2019). The characteristics of effective staff teams in disability services. Journal of Policy and Practice in Intellectual Disabilities. https://doi.org/10.1111/jppi.12280

Grynszpan, O., Weiss, P. L., Perez-Diaz, F., \& Gal, E. (2014). Innovative technology-based interventions for autism spectrum disorders: A meta-analysis. Autism, 18(4), 346-361. https://doi.org/10.1177/ 1362361313476767

Harrower, J. K., \& Dunlap, G. (2001). Including children with autism in general education classrooms: A review of effective strategies. Behavior Modification, 25(5), 762-784. https://doi.org/10.1177/ 0145445501255006

Hill, C., Keville, S., \& Ludlow, A. K. (2021). Inclusivity for children with autism spectrum disorders: Parent's reflections of the school learning environment versus home learning during COVID-19. International Journal of Developmental Disabilities. https://doi.org/10.1080/20473869.2021.1975253 
Hirano, S. H., Yeganyan, M. T., Marcu, G., Nguyen, D. H., Boyd, L. A., \& Hayes, G. R. (2010). vSked: Evaluation of a system to support classroom activities for children with autism. Proceedings of the SIGCHI Conference on Human Factors in Computing Systems. https://doi.org/10.1145/17533 26.1753569

Howlin, P., \& Magiati, I. (2017). Autism spectrum disorder: Outcomes in adulthood. Current Opinion in Psychiatry, 30(2), 69-76. https://doi.org/10.1097/YCO.0000000000000308

Hunt, P., \& McDonnell, J. (2007). Inclusive education. In S. L. Odom, R. H. Horner, M. E. Snell, \& J. B. Blacher (Eds.), Handbook of developmental disabilities (pp. 269-291). The Guilford Press.

Jahromi, L. B., Bryce, C. I., \& Swanson, J. (2013). The importance of self-regulation for the school and peer engagement of children with high-functioning autism. Research in Autism Spectrum Disorders, 7(2), 235-246. https://doi.org/10.1016/j.rasd.2012.08.012

Jury, M., Perrin, A. L., Desombre, C., \& Rohmer, O. (2021). Teachers' attitudes toward the inclusion of students with autism spectrum disorder: Impact of students' difficulties. Research in Autism Spectrum Disorders, 83, 101746. https://doi.org/10.1016/j.rasd.2021.101746

Kurth, J. A., Love, H., \& Pirtle, J. (2019). Parent perspectives of their involvement in IEP development for children with autism. Focus on Autism and Other Developmental Disabilities. https://doi.org/10.1177/ 1088357619842858

Lee, C. S., Lam, S. H., Tsang, S. T., Yuen, C. M., \& Ng, C. K. (2018). The effectiveness of technologybased intervention in improving emotion recognition through facial expression in people with autism spectrum disorder: A systematic review. Review Journal of Autism and Developmental Disorders, 5(2), 91-104. https://doi.org/10.1007/s40489-017-0125-1

Lengwiler, M. (2008). Participatory approaches in science and technology: Historical origins and current practices in critical perspective. Science, Technology, \& Human Values, 33(2), 186-200. https://doi. org/10.1177/0162243907311262

Long, J., Panese, J., Ferguson, J., Hamill, M. A., \& Miller, J. (2017). Enabling voice and participation in autism services: Using practitioner research to develop inclusive practice. Good Autism Practice $(G A P), 18(2), 6-14$.

Magasi, S., Wong, A., Gray, D. B., Hammel, J., Baum, C., Wang, C. C., \& Heinemann, A. W. (2015). Theoretical foundations for the measurement of environmental factors and their impact on participation among people with disabilities. Archives of Physical Medicine and Rehabilitation, 96(4), 569-577. https://doi.org/10.1016/j.apmr.2014.12.002

May, T., Bernie, C., Marty, S., Sutherland, R., Roberts, J. M., \& Williams, K. (2019). Autism, health and education: Models and systems for working together. In R. Jordan, J. M. Roberts, \& K. Hume (Eds.), The SAGE handbook of autism and education (pp. 331-339). SAGE Publications Ltd.

Mazon, C., Fage, C., \& Sauzéon, H. (2019). Effectiveness and usability of technology-based interventions for children and adolescents with ASD: A systematic review of reliability, consistency, durability, and generalization related to the effects of intervention. Computers in Human Behavior, 93, 235-251. https://doi.org/10.1016/j.chb.2018.12.001

McCurdy, E. E., \& Cole, C. L. (2013). Use of a peer support intervention for promoting academic engagement of students with autism in general education settings. Journal of Autism and Developmental Disorders, 44(4), 1-11. https://doi.org/10.1007/s10803-013-1941-5

Minke, K. M., Sheridan, S. M., Kim, E. M., Ryoo, J. H., \& Koziol, N. A. (2014). Congruence in parentteacher relationships: The role of shared perceptions. The Elementary School Journal, 114(4), 527546. https://doi.org/10.1086/675637

National Academies of Sciences, Engineering, and Medicine. (2018). Learning through citizen science: Enhancing opportunities by design. National Academies Press.

Odom, S. L., Thompson, J. L., Hedges, S., Boyd, B. A., Dykstra, J. R., Duda, M. A., \& Bord, A. (2015). Technology-aided interventions and instruction for adolescents with autism spectrum disorder. Journal of Autism and Developmental Disorders, 45(12), 3805-3819. https://doi.org/10.1007/ s10803-014-2320-6

Olmstead, C. (2013). Using technology to increase parent involvement in schools. TechTrends, 57(6), 28-37.

Park, M., \& Chitiyo, M. (2011). An examination of teacher attitudes towards children with autism. Journal of Research in Special Educational Needs, 11(1), 70-78. https://doi.org/10.1111/j.1471-3802.2010. 01181.x

Parmigiani, D., Benigno, V., Giusto, M., Silvaggio, C., \& Sperandio, S. (2020). E-inclusion: Online special education in Italy during the Covid-19 pandemic. Technology, Pedagogy and Education. https://doi. org/10.1080/1475939X.2020.1856714

Patterson, S. Y., Smith, V., \& Mirenda, P. (2012). A systematic review of training programs for parents of children with autism spectrum disorders: Single subject contributions. Autism, 16(5), 498-522. https:// doi.org/10.1177/1362361311413398 
Petretto, D. R., Masala, I., \& Masala, C. (2020). Special educational needs, distance learning, inclusion and COVID-19. Education Sciences, 10(6), 154. https://doi.org/10.3390/educsci10060154

Prado, C. (2013). Le coût économique et social de l'autisme, les avis du conseil économique, social et environnemental. Journal Officiel de la République Française (Mandature 2010-2015-Séance du 9 octobre 2012). Retrieved from http://www.lecese.fr/travaux-publies/le-cout-economique-et-social-de-lauti sme

Rahimi, N., \& Ibarra, M. (2014). A review of multiple user center design methods for new product development in smart and connected health applications. Proceedings of PICMET'14 Conference: Portland International Center for Management of Engineering and Technology; Infrastructure and Service Integration (pp. 3498-3510).

Reed, P., \& Osborne, L. A. (2014). Mainstream education for children with autism spectrum disorders. In J. Tarbox, D. Dixon, P. Sturmey, \& J. Matson (Eds.), Handbook of early intervention for autism spectrum disorders (autism and child psychopathology series (pp. 447-485). Springer.

Robb, N., Boyle, B., Politis, Y., Newbutt, N., Kuo, H. J., \& Sung, C. (2021). Participatory technology design for autism and cognitive disabilities: A narrative overview of issues and techniques. In A. L. Brooks, S. Brahman, B. Kapralos, A. Nakajima, J. Tyerman, \& L. C. Jain (Eds.), Recent advances in technologies for inclusive well-being: virtual patients, gamification and simulation (intelligent systems reference library (Vol. 196, pp. 469-485). Springer International Publishing.

Roberts, J., \& Simpson, K. (2016). A review of research into stakeholder perspectives on inclusion of students with autism in mainstream schools. International Journal of Inclusive Education, 20(10), 10841096. https://doi.org/10.1080/13603116.2016.1145267

Ryan, R. M., \& Deci, E. L. (2020). Intrinsic and extrinsic motivation from a self-determination theory perspective: Definitions, theory, practices, and future directions. Contemporary Educational Psychology, 61, 101860. https://doi.org/10.1016/j.cedpsych.2020.101860

Sandoval, W. A., \& Bell, P. (2004). Design-based research methods for studying learning in context: Introduction. Educational Psychologist, 39(4), 199-201.

Schultz, T. R., Able, H., Sreckovic, M. A., \& White, T. (2016). Parent-teacher collaboration: Teacher perceptions of what is needed to support students with ASD in the inclusive classroom. Education and Training in Autism and Developmental Disabilities, 51(4), 344-354.

Serna, R. W., Lobo, H. E., Fleming, C. K., Fleming, R. K., Curtin, C., Foran, M. M., \& Hamad, C. D. (2015). Innovations in behavioral intervention preparation for paraprofessionals working with children with autism spectrum disorder. Journal of Special Education Technology, 30(1), 1-12. https://doi.org/ $10.1177 / 016264341503000101$

Spinuzzi, C. (2005). The methodology of participatory design. Technical Communication, 52(2), $163-174$.

Tucker, V., \& Schwartz, I. (2013). Parents' perspectives of collaboration with school professionals: Barriers and facilitators to successful partnerships in planning for students with ASD. School Mental Health, 5(1), 3-14. https://doi.org/10.1007/s12310-012-9102-0

Van Hees, V., Moyson, T., \& Roeyers, H. (2015). Higher education experiences of students with autism spectrum disorder: Challenges, benefits and support needs. Journal of Autism and Developmental Disorders, 45(6), 1673-1688. https://doi.org/10.1007/s10803-014-2324-2

Whiteneck, G., \& Dijkers, M. P. (2009). Difficult to measure constructs: Conceptual and methodological issues concerning participation and environmental factors. Archives of Physical Medicine and Rehabilitation, 90(11), S22-S35. https://doi.org/10.1016/j.apmr.2009.06.009

World Health Organization [WHO]. (2001). International classification of functioning, disability, and health $(I C F)$. World Health Organization. Retrieved from https://apps.who.int/iris/handle/10665/42407

World Health Organization [WHO]. (2007). International classification of functioning, disability, and health-children and youth (ICF-CY). World Health Organization. Retrieved from https://apps.who. int/iris/handle/10665/43737

Wróbel, M., \& Romanowski, A. (2015). Guidelines for designing products and services for users with special needs by design thinking method. In J. Lewandowski, A. Polak-Sopińska, \& K. Boczkowska (Eds.), Ergonomics for people with disabilities-Social and occupational integration (pp. 98-114). Lodz University of Technology.

Publisher's Note Springer Nature remains neutral with regard to jurisdictional claims in published maps and institutional affiliations. 
Cécile Mazon obtained in 2019 a PhD degree in cognitive sciences with a specialization on designing and evaluating digital tools to promote school inclusion of children with ASD and cognitive disabilities. She currently works as an assistant professor at the University of Bordeaux, and works with the Flowers team (Inria).

Kattalin Etchegoyhen is speech therapist at the Charles Perrens hospital of Bordeaux and she obtained in 2015 a Master degree in cognitive Science with a specialization in the Needs analysis of children with ASD for their school inclusion.

Isabeau Saint-Supery is $\mathrm{PhD}$ student in cognitive sciences at the university of Bordeaux and currently worked on designing and evaluating the ToGather web application. Graduated with a master degree in this field, she completed her course with a year of professional license in the field of IT project management.

Anouck Amestoy is paedopyschiatrist at the Charles Perrens hospital of Bordeaux and she obtained in 2013 a $\mathrm{PhD}$ degree in cognitive Science with a specialization in the Face perception in children with ASD. She is currently the head of paedopsychiatry services at the Charles Perrens hospital and her research is performed in the Neuroimaging and human cognition team at the INCIA lab (Bordeaux, France).

Manuel Bouvard is paedopyschiatrist at the Charles Perrens hospital of Bordeaux and he is professor in paedopsychiatry at the University of Bordeaux. He is the head of the Department of Child Psychiatry of the Charles Perrens hospital of Bordeaux and his research is performed in the Neuroimaging and human cognition team at the INCIA lab (Bordeaux, France) .

Charles Consel is professor of computer science at the Bordeaux National Polytechnic Institute (BordeauxINP, France) and member of the Bordeaux Laboratory of Research in Informatics (LaBRI, France). His fields of research are software engineering and software orchestration, especially in their application (IoT) for cognitive disability and aging.

Hélène Sauzéon is professor of psychology and cognitive science at the University of Bordeaux and member of the Flowers research team of Inria. Her fields of research are digital technology for cognition and cognitive disorders, especially in inclusive education. 